\title{
Os pronomes e seus traços em línguas da família Pano
}

\author{
Pronouns and their features in the Panoan languages
}

\author{
Jaqueline dos Santos Peixoto \\ Universidade Federal do Rio de Janeiro
}

\begin{abstract}
Our aim is to study the features of pronominal systems in Matsés, Marubo, Kaxinawá and Shipibo-Konibo, languages of the Panoan family. Dealing with data from secondary sources, we propose that the four pronominal systems be interpreted from a theoretical framework which explains linguistic variation in terms of formal features within grammar. The concept that the morphosyntactic properties of pronouns are explained through grammatical features reveals that, in Marubo, Kaxinawá and Shipibo-Konibo, the similarity of the pronominal systems reflects the fact that the three systems share the same set of features in functional nucleus $\mathbf{D}$, and express number through the projection of a $\mathbf{Q P}$ within the DP; in Matsés, the asymmetry between the first and second person pronouns with the third person pronoun is substituted by structural symmetry.
\end{abstract}

\section{Keywords}

Phi-features, Pronouns, Panoan languages

\section{Resumo}

Nosso objetivo é realizar um estudo dos traços dos sistemas pronominais em Matsés, Marubo, Kaxinawá e Shipibo-Konibo, línguas pertencentes à família Pano. Lidando com dados de fontes secundárias, propomos que os quatro sistemas pronominais sejam interpretados com base em um quadro teórico que explica a variação 
linguística em termos de traços formais com interpretação na gramática. A ideia de que as propriedades morfossintáticas dos pronomes são explicadas com base nos traços gramaticais revela que em Marubo, Kaxinawá e Shipibo-Konibo a proximidade dos sistemas pronominais reflete o fato de os três sistemas compartilharem o mesmo conjunto de traços no núcleo funcional $\mathbf{D}$ e expressarem número através da projeção de um QP no interior do DP; em Matsés, a assimetria da $1^{\mathrm{a}}$ e $2^{\mathrm{a}}$ pessoas com a $3^{\mathrm{a}}$ pessoa é substituída pela simetria estrutural.

\section{Palavras-chave}

Traços-phi, Pronomes, Línguas Pano 


\section{Introdução}

$\mathrm{E}$ ste trabalho ${ }^{1}$ tem como objetivo divulgar os resultados de um estudo dos traços dos pronomes em membros da família linguística Pano. ${ }^{2}$ Nosso estudo focaliza principalmente o Matsés, língua que tem representantes no Brasil e no Peru, o Marubo, língua indígena brasileira falada por um grupo que habita as cabeceiras dos rios Ituí e Curuçá, no vale do rio Javari (lado brasileiro da região amazônica), o Kaxinawá, língua cujos falantes habitam as terras interfluviais baixas da Amazônia localizadas no Brasil e no Peru, e o ShipiboKonibo, língua Pano da Amazônia peruana.

Para realizarmos nosso objetivo, incorporamos os resultados dos trabalhos de Abney (1987) e Ritter (1995). Abney explica a diferença entre o nome e os pronomes mostrando que os últimos são destituídos da projeção de um NP. O autor baseia sua proposta na análise do sintagma nominal como a projeção de um núcleo D(eterminante), e na crença de os pronomes serem essencialmente a projeção da mesma categoria $\mathbf{D}$. Já Ritter acredita que a diferença entre os pronomes e a concordância verbal não esteja no contraste entre as categorias, mas no papel que desempenham na sintaxe. A ideia de que a diferença entre pronomes e a concordância verbal seja sintática é corroborada por Chomsky (1999). No design minimalista da linguagem, a concordância verbal é tratada como um efeito de superfície fonética causado pela valoração e remoção dos traços-phi presentes no núcleo $\mathbf{T}$ e consequente valoração e remoção do Caso estrutural não interpretável presente em termos nominais. Já os traços-phi dos pronomes que são sempre interpretáveis já estariam valorados desde o início e não precisariam ser removidos da computação sintática das línguas naturais.

A articulação entre os trabalhos de Ritter e Abney nos permite tratar os pronomes e a concordância como membros da categoria $\mathbf{D}$, uma vez que compartilham o mesmo feixe de traços, isto é, são caracterizados pela presença dos chamados traços-phi (phi-features), além do próprio traço categorial. Essa articulação permite ainda separar o nome do pronome, na medida em que 
somente o primeiro é caracterizado pela projeção do sintagma nominal. As diferenças na organização dos traços morfossintáticos nos pronomes são investigadas à luz das ideias de Harley e Ritter (2002), que estendem a proposta da geometria de traços da fonologia aos traços de pessoa e número. A geometria de traços é uma abordagem autossegmental que reflete aspectos funcionais como hierarquia e conjunto dos traços. A hierarquia indica que os traços não estão todos em mesmo plano, revelando, inclusive, sua dependência. A ideia de conjunto serve para mostrar quais traços estão sujeitos às mesmas condições ou restrições. A proposta de uma geometria de traços morfossintáticos tem como vantagem explicar a variação interlinguística dos pronomes com base em uma configuração particular no que se refere aos traços de pessoa e número.

A comparação sintática entre línguas da família Pano mostra que um grupo de línguas compartilha o mesmo sistema de traços no núcleo funcional D e expressa a noção de número através da projeção de um QP (Sintagma Quantificador) no interior do DP (Sintagma Determinante); enquanto, em um outro grupo, a assimetria da $1^{\mathrm{a}}$ e $2^{\mathrm{a}}$ pessoas com a $3^{\mathrm{a}}$ pessoa é substituída por uma simetria estrutural.

\section{Quadro teórico: núcleo funcional $D$ e a estrutura do DP}

Abney (1987) reinterpreta o sintagma nominal como a projeção de uma categoria D. Os membros da categoria $\mathbf{D}$ são tradicionalmente constituídos pelos traços de número e gênero, traços comuns do nome, pelo traço de pessoa, traço do pronome, além do próprio traço categorial. Em seu trabalho, ${ }^{3}$ a diferença entre nomes e pronomes é explicada pela ausência da projeção de NP; somente os primeiros são a projeção estendida de $\mathbf{N}$. Abney considera os pronomes como os exemplos de categorias constituídas unicamente pela projeção de um núcleo D. Ritter (1995), por sua vez, incorpora os avanços alcançados na investigação da estrutura do DP e defende que a diferença entre os pronomes e a concordância não reside no contraste entre categorias, mas no papel que desempenham na sintaxe. Assumindo que o mesmo conjunto de traços nominais (traços-phi) atua tanto nos pronomes quanto na concordância, a autora defende que a investigação da organização das categorias nominais pode fornecer insights sobre as diferenças internas a cada sistema. As diferenças internas a cada subcategoria/sistema e as diferenças interlinguísticas são explicadas na 
organização interna dos traços nominais no DP e nos núcleos aos quais cada traço se associa. ${ }^{4}$ A organização interna e a associação dos traços-phi nos núcleos funcionais permite prever as estruturas vistas em (i). As configurações em (i) indicam que, apesar do fato de todo DP poder ser constituído pelo conjunto completo de traços-phi, o mapeamento estrutural desses traços nos núcleos funcionais é variável. Assim, na configuração em (ia), os traços [pessoa], [número] e [gênero] são realizados no núcleo D; na configuração em (ib), os traços morfossintáticos de pessoa e número encontram-se associados a núcleos funcionais diferentes, D e Num; e, na configuração estrutural em (ic), o gênero aparece como um traço que caracteriza o nome.

\section{(i) Organização dos traços-phi no DP}

(a)

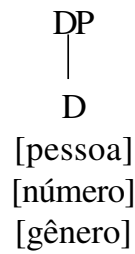

(b)

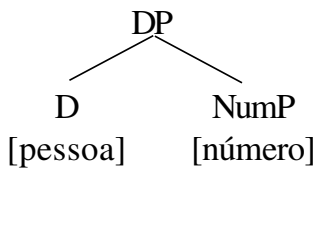

(c)

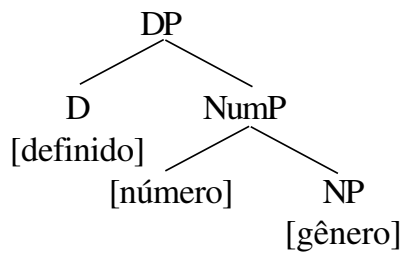

As configurações estruturais acima representam uma proposta de generalização das possibilidades de organização dos traços-phi no DP encontradas nas línguas naturais. Sua base conceitual é fornecida pelos trabalhos que analisam os membros da categoria $\mathbf{D}$ como núcleos de seu próprio sintagma. Já sua base empírica é fornecida pelas línguas da família Pano sob investigação. Essas configurações estruturais também recebem suporte teórico na geometria dos traços morfossintáticos desenvolvida por Harley e Ritter (2002). Em seu trabalho, as autoras propõem uma geometria para os traços de pessoa e número associados à categoria dos pronomes. A organização hierárquica da geometria dos traços morfossintáticos é fornecida pela GU. À semelhança dos traços fonológicos, essa geometria permite fazer uma série de previsões sobre os sistemas pronominais e a concordância nas línguas naturais. Algumas dessas previsões vão ao encontro das três possibilidades de organização dos traços-phi no DP supra-apresentadas.

A geometria dos traços morfossintáticos proposta por Harley e Ritter é mostrada em (ii). Nessa geometria, os traços morfossintáticos encontram-se divididos em três grandes nódulos: o nódulo participante, o nódulo individualização 
e o nódulo classe. O nódulo participante fornece as interpretações referentes às noções de pessoa. Nesse nódulo, a $1^{\mathrm{a}}$ e a $2^{\mathrm{a}}$ pessoa são representadas pelos subnódulos falante e ouvinte, respectivamente. A ausência desses subnódulos tem como interpretação default a $3^{\mathrm{a}}$ pessoa. O nódulo individualização fornece as interpretações referentes à noção de número. A organização dos subnódulos grupo, mínimo e aumentado no nódulo individualização cria as distinções entre as noções de singular, plural e dual. O nódulo classe fornece as interpretações referentes a gênero e a outras noções utilizadas para expressar a classe à qual pertence uma palavra. As noções realizadas pelos traços morfossintáticos de pessoa, gênero e número dependem da organização interna dos nódulos maiores participante, individualização e classe. Embora a organização interna desses nódulos esteja sujeita à variação interlinguística, a geometria de traços proposta prevê uma hierarquia universal para os traços-phi. A organização universal dos traços [pessoa], [número] e [gênero] no DP é um pressuposto teórico deste trabalho.

(ii) Geometria dos traços dos pronomes

Expressão referencial (=Pronome)

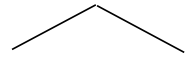

Participante Individualização

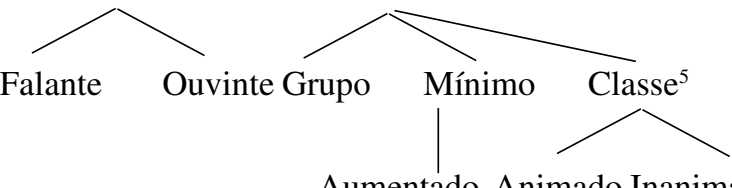

Aumentado Animado Inanimado/Neutro

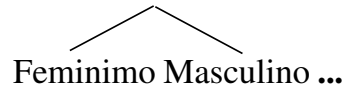

O fato de o nódulo Individualização dominar o nódulo Classe revela uma dependência deste último nódulo pelo primeiro. Harley e Ritter (2002, p. 514) explicam que essa dependência é registrada pelo universal 36 de Greenberg, segundo o qual "se uma língua possui categoria de gênero então ela possui categoria de número". 


\section{Os pronomes e seus traços em línguas da família Pano}

\subsection{Núcleo funcional D a estrutura do DP em Matsés}

O pressuposto minimalista de que a variação interlinguística é um problema relativo às propriedades formais da $\mathbf{G} \mathbf{U}$ coloca-nos diante do imperativo de investigar as propriedades não substantivas dos traços gramaticais que compõem os núcleos funcionais das gramáticas particulares. Diferenças na estrutura dos traços dos núcleos funcionais são explicadas pelas propriedades morfossintáticas exibidas por categorias como concordância, negação, tempo, modo e aspecto. Neste trabalho, realizamos uma investigação dos núcleos funcionais e dos traços formais que compõem esses núcleos em membros da categoria D. Para tanto, entendemos, como Ritter (1995), que os pronomes e a concordância sejam membros de mesma categoria D. O sintagma determinante é uma projeção do núcleo D. O núcleo $\mathbf{D}$ é uma categoria funcional associada aos membros da classe determinante, como artigos, demonstrativos, possessivos e quantificadores, elementos que aparecem à esquerda do nome. Além de compartilharem propriedades estruturais, os membros dessa classe compartilham propriedades semânticas. Semanticamente, os membros dessa classe apresentam o traço [definido]. A ideia é a de que tanto os pronomes quanto os nomes sejam a projeção do núcleo $\mathbf{D}$. A diferença observada na literatura é a de que os pronomes sejam DPs que não projetam NP. Em outras palavras, somente os nomes são a projeção estendida de N, istoé, um NP aumentado pelas camadas funcionais. ${ }^{6}$ Essa diferença entre os pronomes e os nomes explica a ausência dos traços nominais como gênero e também o número ${ }^{7}$ nos pronomes e na concordância. Essas duas categorias podem ser tratadas como DPs que projetam apenas o núcleo funcional D.

Os membros da categoria $\mathbf{D}$ são tradicionalmente constituídos pelos traços nominais de número e gênero, pelo traço de pessoa, além do próprio traço categorial. $\mathrm{O}$ feixe de traços especificados pelo núcleo $\mathbf{D}$ (traços-phi), assim como sua estrutura interna, depende das propriedades morfossintáticas exibidas pelos sistemas pronominais particulares e pelos sistemas de concordância presentes nas línguas naturais. O mapeamento semântico dos traços-phi esclarece como cada traço contribui com a interpretação dos sintagmas determinantes de um modo particular. A variação interlinguística no mapeamento semântico desses traços indica que as línguas naturais se apropriam de forma particular do conjunto de traços-phi fornecidos pela GU. O sistema de pronomes 
pessoais do Matsés confirma a ideia de que os traços comumente associados a cada categoria gramatical não precisam estar todos presentes ou serem realizados nessa categoria. As formas livres dos pronomes pessoais da língua Matsés são apresentadas no quadro a seguir (ver (iii)) cuja organização precisa levar em consideração as noções gramaticais de pessoa e de número, além da noção de caso morfológico.

(iii) Sistema de pronomes pessoais

\begin{tabular}{|l|c|c|c|c|}
\cline { 2 - 5 } \multicolumn{1}{c|}{} & \multicolumn{2}{c|}{ Singular/Dual } & \multicolumn{2}{c|}{ Plural } \\
\cline { 2 - 5 } \multicolumn{1}{c|}{} & Absolutivo & Ergativo & Absolutivo & Ergativo \\
\hline 1a pessoa & ubi & unbi & \multicolumn{2}{c|}{ nuki } \\
\hline 2a pessoa & mibi & minbi & mibi & minbi \\
\hline
\end{tabular}

O quadro supra-apresentado contém apenas as formas pronominais consensuais dos argumentos verbais da língua sob investigação. É importante esclarecer que o consenso na identificação e descrição dos pronomes de primeira e segunda pessoa não é estendido à terceira pessoa. Enquanto Fleck (2003) identifica para a terceira pessoa uma forma nula (terceira pessoal referencial) e outra plena (terceira pessoa correferecial (abi/anbi ' 4 a pessoa abs./erg.), Dorigo (1992) apresenta um quadro muito mais numeroso para essa pessoa (uit ' $3^{\mathrm{a}}$ p. abs. masc. sg.'; t t firo ' $3^{\mathrm{a}}$ p. abs. fem. sg.; uiti-n ' $3^{\mathrm{a}}$ p. erg. masc. sg.;

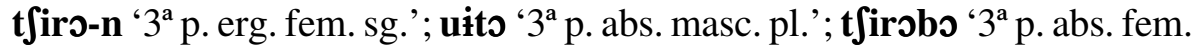
pl.'; uito-n ‘ $3^{\text {a }}$ p. erg. masc. pl.'; t t firobo-n ‘ $3^{\text {a }}$ p. erg. fem. pl.’). A razão desse quadro é mostrar que o sistema pronominal pessoal Matsés garante somente o contraste paradigmático sobre a informação gramatical referente à pessoa - que é o traço do pronome. A ausência da marca /-n/ em/nuki/ ( $2^{\mathrm{a}}$ p. pl.) aponta para o fato de a informação sobre o caso morfológico não ser estendida a todas as pessoas. A própria noção de número não é regularmente incorporada à morfologia pronominal. Fleck (2003, capítulo 4, seção 4.4.1) mostra que o plural pronominal manifestado através do morfema/-bo/ seria opcional em formas arcaicas dos pronomes pessoais, como em /mitso-bo/ ( $2^{\mathrm{a}} \mathrm{p}$.-pl.), e geraria agramaticalidade nas demais formas. Os plurais /mibi-bo/ ( $2^{\mathrm{a}} \mathrm{p}$. pl.) e /minbi-bo/ ( $2^{\mathrm{a}} \mathrm{p}$. pl.erg.) seriam avaliados como formas agramaticais dos pronomes pessoais, uma vez que foram rejeitados pelos falantes nativos consultados em sua amostra. $\mathrm{O}$ autor 
identifica em seus dados uma ambiguidade sistemática entre o singular, dual e plural - somente parcialmente resolvida na presença do formativo $/ \mathrm{t} \int \mathrm{edo} /{ }^{8}$ resultando em estruturas como: /ubi-t $\int \mathrm{edo}$ ('eu também', 'eu et cetera') e / minbi-t $\int$ edo/ ('vocês também', 'vocês et cetera'). Dorigo (1992, seção 3.3.2.2), mesmo tratando /-bo/ ${ }^{9}$ como um morfema regular de plural dos pronomes (/mibibo/ $2^{\mathrm{a}}$ p.pl.abs; /minbi-bo/ $2^{\mathrm{a}}$ p.pl.erg), identifica em seus dados a opcionalidade desse morfema quando a informação gramatical que veicula aparece codificada pelo verbo. Os dados coletados por Dorigo não registram agramaticalidade causada pela presença do morfema /-bo/ como um afixo do pronome pessoal (ver (1)). Os dados da autora demonstram também que a ausência desse morfema pode ser compensada pela realização da noção semântico-gramatical de número como um morfema da própria base verbal (conferir (2)).
(1) mi'bibə॰ $^{\bullet} \wedge$ 'dẽsa_t?
mibi-bo dansa- $\varepsilon$
$2^{\text {a }}$ p.-pl. dançar-não-pass.
'Vocês estão dançando.'

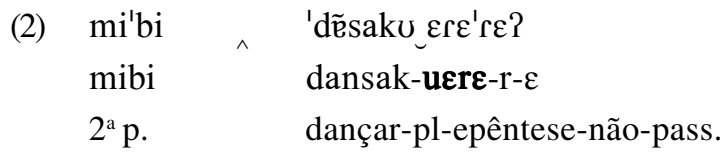

'Vocês estão dançando'

Fleck (2003, seção 5.3.2), além de apontar a ambiguidade das noções de singular, dual e plural, nos nomes e pronomes, avança ao registrar que a presença de estratégias de marcação de número, seja em nomes, seja em pronomes, não realiza a noção ordinária de plural. Tais estratégias confirmam a exclusão da categoria número do sistema de pronomes pessoais da língua Matsés. As restrições com que operam as próprias estratégias de 'pluralização' sustentam a hipótese de que as distinções semânticas de singular, dual e plural sejam resultado da organização do traço referente à pessoa. Os processos de pluralização e singularização realizados com o formativo/-ben/ ('sozinho') e com o formativo quantitativo/daidi/ ('ambos') nos levam a excluir o traço de número do sistema de pronomes pessoais da língua. $\mathrm{O}$ formativo/-ben/ ('sozinho') aparece junto aos pronomes que carregam traço de $1^{\text {a }}$ pessoa (neste caso, /ubi/) e $2^{\text {a }}$ pessoa (neste caso, /mibi/), estando semanticamente impedido de ocorrer junto 
a /nuki/ ('nós'), ou a qualquer forma pronominal que carregue juntos os traços de $1^{\mathrm{a}}$ e $2^{\mathrm{a}}$ pessoas (ver conjunto (3), dados de FLECK, 2003, p. 263). ${ }^{10} \mathrm{~A}$ compatibilidade entre as formas que carreguem juntos os traços de $1^{\mathrm{a}}$ e $2^{\mathrm{a}}$ pessoas e a pluralização realizada por /daidi/ ('ambos') torna possível a combinação semântica entre esse formativo e o pronome/nuki/ (ver conjunto (4), FLECK, 2003, seção 8.3.4). A aplicação dos mecanismos de pluralização e singularização nas formas pessoais dos pronomes obedece aos seguintes critérios: (a) formativo/-ben/ ('sozinho') - combina-se somente com pronomes que portem apenas um traço de pessoa; e (b) formativo quantitativo/daidi/ ('ambos') - não impõe restrições aos traços portados pelos pronomes. Sendo o formativo/-ben/ ('sozinho') a realização de uma estratégia de singularização, é natural que seja semanticamente incompatível com qualquer pronome que comporte estruturalmente dois traços de pessoa. A pluralização com/daidi/ ('ambos'), por sua vez, é bem-vinda para todas as formas pronominais. A distribuição prevista para as formas de pluralização e singularização é compatível com o traço de terceira pessoa presente nas formas pronominais /abi/ $\left(3^{\mathrm{a}} \mathrm{p} \text {. abs. correferencial }\right)^{11}$ (ver conjunto (5), dados de FLECK, 2003, capítulo 4, seção 4.4.5.1).

(3) -ben 'sozinho'

(a) u-ben-tsëc

u-ben-tsik

$1^{\text {a }}$ p.-sozinho-enfático

'Eu sozinho.' (b) mi-ben-tsëc

mi-ben-tsik

$1^{\text {a }}$ p.-sozinho-dim. vir-inferencial

'You came by yourself'

'Você veio sozinho.'

(4) daidi 'ambos'
(a) ubi
daëdi
(b) mibi
daëdi
(c) nuqui
daëdi
ubi
daidi
mibi
dałdi
nuki daidi
$1^{a}$ p. abs. Ambos
$2^{\mathrm{a}}$ p.abs.
Ambos
$1^{\mathrm{a}} \mathrm{p}+2^{\mathrm{a}} \mathrm{p}$. Ambos
'both of us $(1+3)$ '
'both of you'
'both of us $(1+2)$ '
'Eu e ele (ambos).'
'Vocês (ambos).'
'Eu e você (ambos).' 
(5) -ben 'sozinho'

(a) u-ben-tsëc-bi

ubi ${ }^{12}$-ben-tsik-bi

$1^{\text {a }}$ p.abs.sozinho.DIM.enfático

'Eu sozinho' (b) mi-ben- tsëc

mibi-ben-tsik-

$2^{a}$ p.abs-sozinho.DIM

'You came by yourself.'

'Ele veio por si mesmo (sozinho)'

(c) ambentsëcbi ${ }^{13}$

anbi-ben-tsi-bi

$3^{\text {a }}$ p.-erg.sozinho-DIM.enfático

'He ate alone.'

peosh

pe-o- $\int$

comer-pass. $3^{\mathrm{a}} \mathrm{p}$.

'Ele comeu sozinho.

Os fatos empíricos da língua Matsés nos levam à conclusão de que os pronomes são destituídos de especificação para o traço número. A tarefa é explicar como a pluralização, banida das formas pessoais dos pronomes, pode ser estruturalmente produzida. O quadro (iv) fornece parte da explicação para essa questão, na medida em que permite obter corretamente as noções semânticas de singular e de plural, sem que haja a necessidade de se recorrer ao traço de número. Observa-se nesse quadro que: ${ }^{14}$ (a) /ubi, unbi/ - especificado somente para $1^{\text {a }}$ pessoa-impede qualquer forma de pluralização; (b) /ubi, unbi/-especificado para $1^{\mathrm{a}}$ e opcionalmente para $3^{\mathrm{a}}$ pessoa - admite somente formas exclusivas do plural ('eu e ele' ou 'eu e eles'); (c)/mibi, minbi/- especificado para $2^{\mathrm{a}}$ pessoa-admite as formas de particularização (você), duplicação (vocês dois) e pluralização (vocês); (d) /nuki/ - especificado para $1^{\mathrm{a}} \mathrm{e} 2^{\mathrm{a}}$ pessoas - admite somente formas inclusivas do plural ('eu e você', 'eu e vocês dois' ou 'eu e vocês'); e (e) /abi, anbi/ - especificado para $3^{\text {a }}$ pessoa - admite interpretações de singular (ele) e de plural (eles). A interpretação semântica de número nos pronomes é uma questão de compatibilidade do traço pessoa com as formas de pluralização.

(iv) Sistema de traços dos pronomes pessoais

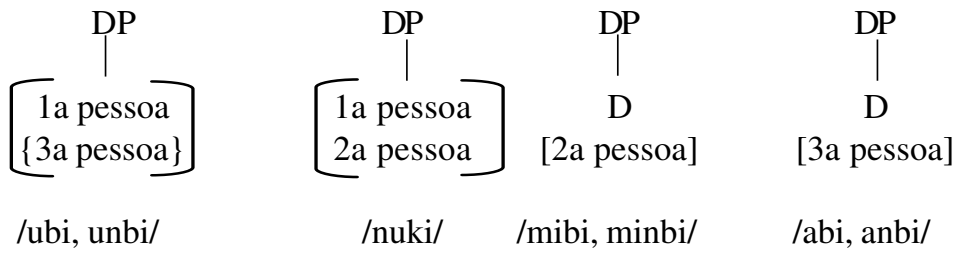


A incompatibilidade entre a pluralização realizada com o morfema /-bo/ e as formas pessoais dos pronomes pode ser, finalmente, compreendida com base nas propriedades exibidas pelos membros da categoria D. O quadro (v) é uma amostra da agramaticalidade gerada pela presença desse morfema nos pronomes pessoais da língua (dados extraídos de FLECK, 2003, seções 4.4.1 e 4.6.1.1). Nas línguas da família Pano, o sufixo /-bo/é documentado como uma forma de plural, embora as evidências o apontem como uma forma de coletivo (homogêneo ou heterogêneo). A agramaticalidade da presença do morfema de plural nos pronomes pessoais pode ser resultado da incompatibilidade entre o sentido referencial definido (determinado) dos pronomes e um sentido referencial indefinido (indeterminado) causado por mecanismos de pluralização. Aexplicação intralinguística para esse fato pode estar na exigência de que os pronomes pessoais em Matsés sejam sempre interpretados como definidos, não se sujeitando a processos de indeterminação (impessoalização) que podem atingir com maior ou menor resistência os pronomes de uma língua.

(v) Coletivo com/-bo/

\begin{tabular}{|l|ll|}
\cline { 2 - 3 } \multicolumn{1}{c|}{} & Absolutivo & Ergativo \\
\hline $1^{\text {a }}$ pessoa & $*$ ubi-bo & $*$ unbi-bo \\
\hline $2^{\text {a }}$ pessoa & $*$ mibi-bo & $*$ minbi-bo \\
\hline $3^{\text {a }}$ pessoa correferencial & $*$ abi-bo & $*$ anbi-bo \\
\hline
\end{tabular}

Se a análise dos pronomes e da concordância como membros de uma mesma categoria $\mathbf{D}$ - tal como propomos para o Matsés - estiver correta, ${ }^{15}$ espera-se reencontrar as mesmas propriedades reveladas pelas formas pessoais dos pronomes na concordância verbal. Em Matsés, a concordância verbal realiza-se com o sujeito de terceira pessoa (nulo ou pleno) ou com o DP nominal, através do morfema / $/$ /. O ponto importante é saber se a hipótese sobre a ausência do traço [número] no sistema pronominal pessoal se mantém para a concordância verbal. A resposta a essa pergunta é dada pelo conjunto de sentenças seguintes (dados de DORIGO, 1992, p. 54 e 81). Percebemos que a terceira pessoa implica necessariamente a presença do morfema /- $\int /$, independentemente de essa pessoa ser pronominal (sentenças (6) e (7)), ou nominal (sentenças (8) e (9)); estar no singular (sentenças (7) e (9)), ou estar no plural (sentenças (6) e (8)). A nossa conclusão é a de que o traço [número] também está ausente no sistema de concordância verbal. 
(6) vu'rõ $\wedge \quad$ a'ra

$\mathrm{kU} \varepsilon^{\prime} \mathrm{s} \rho \mathrm{s}$

uiro-n

ara

kues-o- $\int$

$3^{\mathrm{a}}$ p.pl-erg.

int.

bater-pass. $3^{\mathrm{a}} \mathrm{p}$.

'Eles bateram em você?'

(7) nuน'sนี

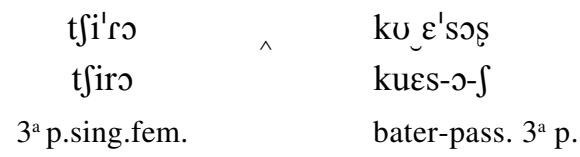

$3^{\text {a }}$ p. sing.-erg.

bater-pass. $3^{\mathrm{a}} \mathrm{p}$.

'Ele bateu nela.'

(8) da'ra'bo mamữ tẽ

ma'mũnõ'das

dara-bo

maminte

maminon-da- $\int$

homem-coletivo.

com a bola

jogar-pass. $-3^{\mathrm{a}} \mathrm{p}$.

'Os homens jogavam bola.'

[A homenzada jogava bola.]

(9)

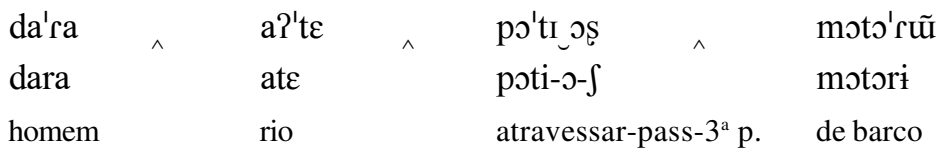

'O homem atravessou o rio de barco.'

O levantamento dos traços-phi dos pronomes pessoais e da concordância na língua em tela apoia a hipótese de essas duas classes de elementos pertencerem à categoria $\mathbf{D}$. Ambos caracterizam-se pela supressão do traço nominal de número. Outra característica compartilhada é a falta do traço nominal de gênero. As evidências são fornecidas pelas sentenças (10), (11) (dados de FLECK, 2003, p. 245), e (12) (dado de DORIGO, 1992, p. 61). A ambiguidade na glosa da forma plena do pronome de terceira pessoa /abi/ ('ele', 'ela', 'eles') e a ausência de restrição semântica do afixo /- $\int /$ fortalecem a ideia de que os pronomes pessoais não comportem o traço de [gênero]. Não é surpreendente que os traços nominais [número] e [gênero] sejam excluídos da categoria $\mathbf{D}$ em Matsés. Abney (1987, p. 281-284) analisa os pronomes como sintagmas determinantes que não projetam sintagma nominal. A estrutura que propõe para os pronomes explica a omissão de traços nominais nas duas classes de elementos identificadas como membros da categoria D. É a ausência de traços nominais 
que permite a proposta de que os pronomes pessoais e a concordância sejam DPs que projetam apenas o núcleo funcional D. A nosso ver, isso é o que acontece com o Matsés.
(10) abi-tsen
cho-o-sh
abi-tsen
t $\int \mathrm{o}-\mathrm{o}-\mathrm{S}$
$3^{\mathrm{a}}$ p.abs-próximo
vir-não.pass-3a p.
'He/she/it/they came next.'
'Ele, ela, isso, eles são os próximos.'
(11) abi
pad-quid
abi
pad-kid
$3^{\mathrm{a}}$ p.abs.
igual.a- nlzd. agt.
'one like him/her/it'
'Um igual a ele/ela/isso.'

(12)

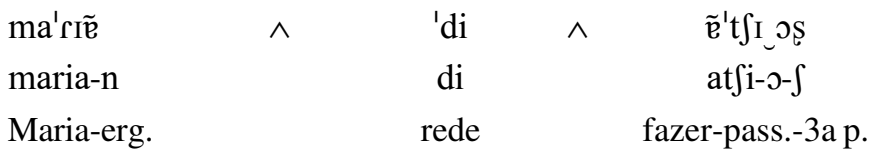

'Maria fez rede.'

A análise dos pronomes pessoais e da concordância como DPs que projetam o núcleo $\mathbf{D}$ não estará completa sem o conhecimento das características distribucionais dos traços que compõem esse núcleo. Os modos de organização estrutural do traço categorial $\mathbf{D}$ e do traço de pessoa nos pronomes e na concordância devem ser motivados nos fatos empíricos atestados nos dados da língua. O tratamento dos pronomes e da concordância como membros da mesma categoria torna inviável a ideia de que sua diferença seja uma questão de variação dos traços associados a si. Na verdade, além da própria diferença sintática entre a concordância e os pronomes, diferença esta que não será explorada neste trabalho, o contraste entre essas categorias é uma consequência natural das relações de pessoa em jogo em cada uma, neste caso, a primeira e segunda pessoa nos pronomes e a terceira pessoa na concordância.

A assimetria existente nas línguas do mundo entre $1^{\mathrm{a}}$ e $2^{\mathrm{a}}$ pessoas com a $3^{\text {a }}$ pessoa contribui para a descoberta dos traços associados ao núcleo funcional projetado pela categoria $\mathbf{D}$ em Matsés. A terceira pessoa em Matsés desvia-se 
das demais pessoas por ser a única a apresentar formas plenas na língua. Esse comportamento desviante da terceira pessoa corresponde às expectativas geradas pelo fecundo debate conduzido por Benveniste sobre a natureza dos pronomes e as relações de pessoa. Diferentemente do que acontece com a primeira pessoa e a segunda pessoa, a terceira pessoa, nessa língua, admite duas realizações: uma realização nula e outra plena. No período simples e nas orações principais, a terceira pessoa pronominal é nula. Nas orações nominalizadas e nas orações subordinadas adverbiais, realiza-se plenamente como /abi/ ( $3^{\mathrm{a}} \mathrm{p}$. abs.) ou /anbi/ ( $3^{\text {a }}$ p. erg.). A forma encoberta do pronome expressa um sujeito temático com referência definida. Já as formas plenas são correferenciais de um constituinte argumental da oração principal. Se os DPs referenciais são a projeção de uma categoria $\mathbf{D}$ que porta o traço [definido], a indicação de um sujeito temático definido é o que se espera de um pronome nulo em sua função referencial. A existência de uma forma plena para a função correferencial da terceira pessoa em orações nominalizadas e subordinadas adverbais pode ser explicada pela necessidade de satisfação de uma condição sintática dessas orações que, ao mesmo tempo em que requer uma interpretação referencial definida para o elemento correferencial, precisa ter sua presença licenciada na sentença encaixada. O licenciamento sintático da terceira pessoa correferencial não pode ser obtido da mesma forma que a terceira pessoa nula nas orações principais. A presença do afixo /-S/ - que marca a concordância do verbo com o pronome encoberto de terceira pessoa - é o elemento que licencia a terceira pessoa encoberta - um fenômeno tratado na literatura como sujeito nulo. $\mathrm{O}$ desaparecimento dessa marca nas orações subordinadas é concomitante ao aparecimento de um DP referencial com ou sem a projeção de NP. Tal característica é recorrente aos três modos de subordinação descritos por Fleck (2003, capítulo 12) - orações nominalizadas, adverbializadas e adjetivais. As formas plenas do pronome de terceira pessoa correferencial nas orações nominalizadas e adverbiais estão em distribuição complementar com a marca de concordância I-S/no verbo, ou seja, ocorrem em contextos gramaticais mutuamente exclusivos. Cabe às formas plenas da terceira pessoa desempenhar o mesmo papel sintático da concordância, banida das formas de subordinação da língua. O banimento da concordância é consequência da natureza nominal do verbo nos mecanismos de subordinação. A nominalização - mecanismo gramatical de criação de estruturas com valor semântico relativo, ao lado da adverbialização e da adjetivação - duas estratégias de obtenção de estruturas com valor subordinado, inviabilizam o 
estabelecimento da concordância com o sujeito temático nulo ou pleno. A utilização da forma plena do pronome de terceira pessoa é um dispositivo empregado por orações adverbializadas e nominalizadas, impedidas de carregarem marca de pessoa, conforme exemplificam os dados abaixo (dados de FLECK, MS). Os dados em (13) mostram que a referência de /anbi/ ( $3^{\text {a }}$ p. erg.) e /abi/ ( $3^{\mathrm{a}} \mathrm{p}$. abs.) é fornecida pelo argumento da oração principal. A terceira pessoa correferencial nos dados em (13) aparece indexada a um argumento expresso da oração principal. Contudo, nada impede que ela esteja coindexada a um argumento não expresso (nulo) da oração principal, como indicam mais adiante os dados em (14).

$$
\text { (a) ambi kues-aid }
$$

matsés-n

pe-en-kio

ik-e-k

anbi kue-said

matses-n

pe-en-kio

ik-e-k

4a p.erg matar-PAC.NLZD-abs Matses- erg comer-NEG-AUM

AUX-NPASS-IND

'A Matsési dois not eat what hei (himself) has killed'

'Matsési não come aquilo que elei próprio matou'

(b) $\quad$ abi

pad-kid]-bëd

debi

cho-o-sh

abi

pad-kid-bid

dedi

t5o-o- $\int$

$4^{\mathrm{a}}$ p. abs ser-parecido-AGT. NLZD-COM:S

DAVY-abs

vir-PASS- $3^{\mathrm{a}}$ p.m

'Davyi came with someone that was like him (e.g. same race or manner)'

'Davyi chegou com alguém que era igual a elei'

Em lugar da forma plena do pronome de terceira pessoa, pode figurar ainda um DP referencial com núcleo D [+definido] e com a projeção de um sintagma nominal, como comprovam as sentenças em (14) (dados extraídos de FLECK, 2003, seção 12.4.3.3). As formas de "relativização", obtidas por meio de adjetivos deverbais, também empregam o recurso de um DP nominal. A natureza existencial dessas construções fornece a razão da exclusão das formas plenas /abi/ ( $3^{\mathrm{a}}$ p. $)$ e /anbi/ ( $3^{\mathrm{a}}$ p. erg.). Os dados referentes às sentenças em (15) (FLECK, 2003, 6.8.2) mostram que, nas estruturas construídas por meio de adjetivos deverbais, não há nada que impeça a emergência de um DP nominal, à semelhança do que acontece com a subordinação adverbial deverbal. $\mathrm{O}$ confronto entre (14c) e (14d) ilustra que o constituinte omitido não precisa ser correferencial com um termo da estrutura encaixada. ${ }^{16}$ 


$\begin{array}{clll}\text { (14) a. debi } & \text { nes-ash } & \emptyset & \text { ush-o-sh } \\ \text { debi } & \text { nes-a } & & \text { uf-o- } \int \\ \text { Davy-abs } & \text { banhar.se-depois:S/A }>\mathrm{S}^{17} & \text { 3a p. } & \text { dormir-pass.-3a p. }\end{array}$

'After bathing, Davy slept.'

'Após se banhar, Davy dormiu.'

b. debi-n

$$
\text { nes-shun }
$$

$\varnothing$

$$
\text { pe-o-sh }
$$

debi-n

$$
\text { pe-o- } \int
$$

Davy-erg.

banhar.se-depois:S/A $>A$

3a p. comer-pass.-3a p.

'After bathing, Davy ate.'

'Após se banhar, Davy comeu.'

$\begin{array}{ll}\text { c. debi } & \text { pe-ash } \\ \text { debi } & \text { pe-a }\end{array}$

Davy-abs. comer-depois:S/A >A

'After eating, Davy slept.'

'Depois de comer, Davy dormiu.'

d. debi

$$
\text { pe-ash }
$$

debi

$$
\text { pe-a }
$$

Davy-abs. comer-depois:S/A >A

'After eating Davy, [the jaguar] slept.'

'Depois de comer Davy, [O jaguar] dormiu.'

$$
\begin{gathered}
\text { ush-o-sh } \\
\text { uf-o- } \int
\end{gathered}
$$

3a p dormir-pass.-3a p.

(15) a. nëid

$$
\text { chonoad-te }
$$

chonoad-tsëcquio

ic-e-c

niid

t onoad-te t onoad-tsikkio

ikek

esse trabalhar-nlzd.inst. trabalhar-derrogativo:adjr. ser-não.pass-ind.

'This job is unpleasant and too much work (lit., "workful”).'

'Esse trabalho é insatisfatório e muito trabalhoso.'

b. bëdi

$$
\text { dacuëd-an-pambo }
$$

ic-e-c

bidi

dakuid-an-panbo

ikek

jaguar ser.assustador-inceptivo-aumentativo:adjr

ser-não.pass.-ind.

'Jaguars are frightening.' (lit., “scare causing”)

'Jaguares são assustadores.' 
A digressão realizada para o exame das características gramaticais das orações formadas de nomes, advérbios e adjetivos deverbais justifica-se na necessidade mais imediata de depreensão dos traços associados ao pronome e à concordância de terceira pessoa. A distribuição complementar entre o pronome e a concordância é informativa dos traços projetados pelo núcleo $\mathbf{D}$. O surgimento das formas plenas de terceira pessoa, nas sentenças com encaixamento, é consequência da inabilidade do verbo na forma nominal de carregar traço de pessoa. ${ }^{18}$ A noção gramatical de pessoa pode ser entendida, assim, como um traço do pronome. As restrições observadas na produção da noção não ordinária de plural nos pronomes pessoais afirmam a presença do traço [definido] nessas formas. As três pessoas são DPs referenciais que projetam uma categoria $\mathbf{D}$ especificada com os traços [pessoa] e [definido]. As formas correferenciais do pronome de terceira pessoa exibem o mesmo feixe de traços apresentado pelos pronomes de primeira pessoa e segunda pessoa. As formas plenas de terceira pessoa apresentam organização estrutural igual a das demais pessoas. A assimetria da $1^{\mathrm{a}}$ e $2^{\mathrm{a}}$ pessoas com a $3^{\mathrm{a}}$ pessoa nula é substituída pela simetria estrutural existente entre as formas plenas dos pronomes pessoais. No quadro (vi), a simetria estrutural entre a $1^{\mathrm{a}}, 2^{\mathrm{a}}$ e $3^{\mathrm{a}}$ pessoas pronominais permite representarmos a organização de seus traços através da mesma estrutura arbórea. Nesse mesmo quadro, a projeção de um núcleo D tem como interpretação default a terceira pessoa no morfema de concordância.

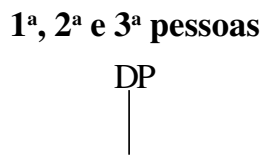

$\mathrm{D}$

\section{$3^{\text {a }}$ pessoa concordância}

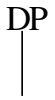

$\mathrm{D}$

[definido]

[pessoa]

\subsection{Núcleo funcional D a estrutura do DP em Marubo}

Em Marubo, o sistema de marcação de caso morfológico interage com os modelos rítmicos da língua. Há duas formas atestadas para a realização morfológica do caso ergativo. Nos monossílabos lexicais e nas palavras paroxítonas e proparoxítonas, a função gramatical do sujeito do verbo transitivo é indicada pela presença de ressonância nasal na vogal mais à direita. A 
nasalização vocálica nos dissílabos é acompanhada pela inversão da proeminência nas palavras que recebem acento na primeira sílaba - o que causa o surgimento de iambos não lexicais. Nas palavras portadoras de acento iâmbico com origem no léxico, o caso ergativo torna-se visível através do aparecimento do afixo /-pa/. A presença desse sufixo também imprime mudanças acentuais na palavra. Outra forma de revelar a função gramatical das palavras é através da afixação do morfema /-tuN/, presente em compostos lexicais formados pelo verbo e seu complemento, em sintagmas nominais complexos, nos quais não é possível marcar exclusivamente o núcleo, e aparecendo, ainda, como parte dos pronomes que seguem o eixo ergativo-absolutivo. Por ser um morfema sem acento, conforma-se com o padrão rítmico geral da língua, não implicando alterações no modelo acentual dos compostos em que aparece. A manifestação da ergatividade pode resultar também no surgimento de uma nova sílaba na palavra. O surgimento de uma sílaba como produto da manifestação do caso morfológico parece estar limitado às palavras com vogal final /i/ e /u/. Nesse caso, a nova sílaba é constituída por onset nasal e por um núcleo que compartilha traços com a vogal final da palavra. A existência de palavras que manifestam caso através da adjunção de uma sílaba extra levou Costa (2000, p.172) a propor a representação /-nV- ${ }_{\mathrm{Al}} /{ }^{19}$ como a forma subjacente do morfema de ergatividade em Marubo. Nessa representação, a marcação do caso ergativo é feita por um morfema silábico constituído por um onset nasal especificado para ponto de articulação e por um núcleo vocálico especificado somente para altura. Essa análise justificase parcialmente nos dados da língua em que a ergatividade é indicada através de uma sílaba extra. Nos casos em que a ergatividade é assinalada apenas através de ressonância nasal vocálica, a nossa preferência, neste trabalho, é indicar na representação fonológica somente o elemento nasal responsável pelo processo de nasalização vocálica. O sistema pronominal da língua Marubo sustenta a interação entre os modelos rítmicos e o sistema de marcação de caso ergativo, como mostra no quadro (vii), resultante de uma adaptação feita com base em Costa (1992, 1998 e 2000). 
(vii) Sistema de pronomes pessoais

\begin{tabular}{|c|c|c|c|c|}
\cline { 2 - 5 } \multicolumn{1}{c|}{} & \multicolumn{2}{c|}{ Singular } & \multicolumn{2}{c|}{ Plural } \\
\cline { 2 - 5 } \multicolumn{1}{c|}{} & Absolutivo & Ergativo & Absolutivo & Ergativo \\
\hline $1^{\text {a }}$ pessoa & ia & i'a-N & nuki & nu'ki-N \\
\hline $2^{\text {a }}$ pessoa & mia & mi'a-N & matu & ma'tu-N \\
\hline $3^{\text {a }}$ pessoa & a & aN-tuN & a-rasi-N & a-rasi- $\mathrm{nV}{ }_{\mathrm{Al}}$ \\
\hline
\end{tabular}

Ao lado de um sistema pronominal que manifesta a presença do caso morfológico, convive um conjunto de formas pronominais dependentes em termos prosódicos (formas clíticas) que não seguem o sistema ergativo-absolutivo da língua, como revela o quadro (viii) (COSTA, 1992, p. 115; 1998, p. 65):

(viii) Formas pronominais dependentes

\begin{tabular}{|c|c|c|}
\cline { 2 - 3 } \multicolumn{1}{c|}{} & Singular & Plural \\
\hline $1^{\mathrm{a}}$ pessoa & $\mathrm{iN}$ & $\mathrm{nuN}$ \\
\hline $2^{\mathrm{a}}$ pessoa & $\mathrm{miN}$ & $\mathrm{maN}$ \\
\hline $3^{\mathrm{a}}$ pessoa & $\mathrm{aN}$ & $\mathrm{atuN}$ \\
\hline
\end{tabular}

A comparação entre o sistema de pronomes pessoais e as formas pronominais dependentes (ver quadros suprarrelacionados) indica que as formas clíticas têm sua origem no sistema pronominal da língua. As formas pronominais dependentes aparecem junto aos verbos e aos nomes, funcionando nos primeiros como concordância anafórica na língua.

O clítico em Marubo duplica os traços-phi do sujeito temático da sentença. As formas pronominais dependentes ocorrem preferencialmente com sujeito gramatical de $1^{\mathrm{a}} \mathrm{e} 2^{\mathrm{a}}$ pessoas de sentenças com verbo transitivo (comparar dados (16) e (17) com o dado (18) (dados de COSTA, 1998, p. 74-76)) e intransitivo com sujeito agente (confrontar (19a) com (19b) (dados de COSTA, 1992, p. 116)). A convivência do clítico com o constituinte que duplica caracteriza $o$ fenômeno descrito na literatura como redobro de clítico. Aduplicação de traços do sujeito temático, no pronome átono, cumpre o mesmo papel sintático da concordância verbal, nas chamadas línguas de sujeito nulo. Em razão desse aspecto, nossa preferência é tratar as formas clíticas da língua como a manifestação da concordância verbal com características gramaticais de pronome. Por apresentar características gramaticais de pronome, podemos 
afirmar que o clítico é a categoria com a qual o núcleo $\mathbf{T}$ entra em relação de checagem do traço $\mathbf{D}$. Na teoria de checagem de traços, o traço $\mathbf{D}$ forte presente no núcleo $\mathbf{T}$ é responsável pelo alçamento do sujeito em direção à posição estrutural de especificador de TP, em uma reinterpretação de EPP(CHOMSKY, 1995). A versão forte desse traço é utilizada para explicar o movimento de constituintes em sintaxe aberta. No desenvolvimento do design minimalista da linguagem, EPP aparece associado a fases fortes. Somente verbos leves, núcleo $\mathbf{v}$-zinho de verbos transitivos e intransitivos inergativos, e o núcleo $\mathbf{T}_{\text {completo' }}$, núcleo $\mathbf{T}$ selecionado por um complementizador pleno ou nulo, podem ter esse traço. Os núcleos que carregam esse traço requerem a presença de um especificador que pode ser satisfeita através da operação de movimento do constituinte mais próximo ou através da operação de concatenação. Diferentemente, Alexiadou e Anagnostopoulou (1998) propõem que EPP esteja sempre presente em qualquer língua. A parametrização diria respeito somente ao modo como esse traço é checado: (a) se pelo sujeito ou qualquer outro constituinte, (b) se pelo verbo em virtude da presença de marcas de concordância. A ideia defendida é a de que a checagem desse traço com o verbo seria mais econômica, uma vez que não exigiria a criação de novas estruturas durante a computação sintática. A proposta adotada neste trabalho é a de que o traço D possa ser checado com o sujeito estrutural da sentença ou com um verbo que carregue concordância anafórica ou pronominal. Na língua Marubo, o verbo, por carregar o clítico pronominal, pode checar esse traço com o núcleo T. Ora, isso é exatamente o que propõe Borer (1986) com a sua teoria do sujeito-I (I-subject), que trata a concordância entre o verbo e o sujeito como a própria manifestação do Caso estrutural. A mesma autora, em trabalho anterior (BORER, 1981), desenvolvido no modelo da Regência e Ligação da Gramática de Princípios e Parâmetros, já interpretava o clítico pronominal como um elemento gramatical capaz de absorver o Caso do núcleo I. A análise do clítico como uma categoria pronominal com a qual o núcleo $\mathbf{T}$ checa traço $\mathbf{D}$ dispensa o alçamento do sujeito pronominal tônico ou nominal para a posição estrutural de especificador de TP. O sujeito poderia, assim, permanecer na posição estrutural de especificador do VP. Contudo, nessa língua, o sujeito à esquerda do verbo aparece em uma posição mais alta na árvore. Há duas posições possíveis para o sujeito gramatical em Marubo, a posição de especificador de TP e a posição de especificador de CP. O movimento do sujeito para especificador de TP ocorreria após o movimento 
dos traços formais do clítico pronominal em direção ao núcleo T. (ALEXIADOU e ANAGNOSTOPOULOU, 2001). Já a presença do sujeito na posição de especificador de TP ocorreria em virtude da ocorrência de um elemento de natureza pronominal na posição que ele normalmente ocuparia. Neste caso, o sujeito seria concatenado e não movido para uma posição acima de TP. Aúnica posição possível para o sujeito impedido de figurar como especificador de TPé a de tópico da sentença. $\mathrm{O}$ sujeito seria, assim, gerado diretamente na posição de tópico, visto que outro constituinte já apareceria na posição normalmente ocupada por ele. Um processo similar ao produzido pelo redobro de clítico em Marubo é analisado por Kallulli (1999). Procurando estabelecer uma correspondência entre a interpretação proposicional e a estrutura informacional da sentença, Kallulli mostra que o clítico em albanês redobra um constituinte localizado em $\mathbf{C P}$.

\begin{tabular}{|c|c|c|c|}
\hline ŭ' & 'miłă & $\tilde{u}^{\prime}$ & 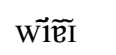 \\
\hline ia-N & mia & iN & wiN-ai \\
\hline sg-erg & 2ap.sg & & \\
\hline
\end{tabular}

'Eu vejo você.'

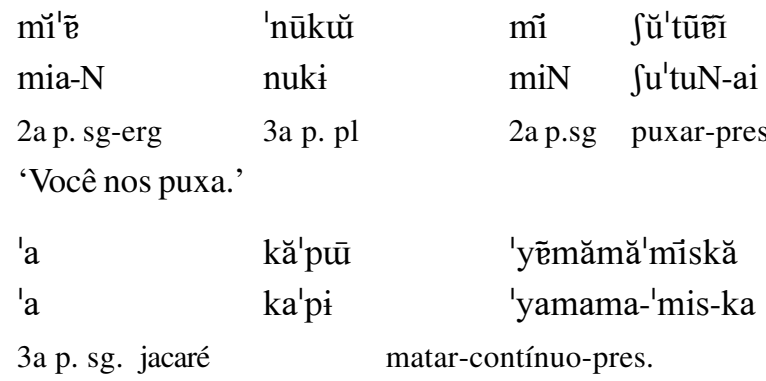

(19) a. 'mỉă

mĩ mŭ'nūă $\mathrm{I}$

mia

miN mu'nu-ai

b. 'wa

mŭ'nūă

'wa

mu'nu-ai

$2^{\mathrm{a}}$ p. sg. $\quad 2^{\mathrm{a}}$ p.sg. dançar-pres/pass.im.

$3^{\mathrm{a}}$ p. sg.

dançar-pres/pass.im.

'Você dança.'

'Ele dança.'

A condição para que haja redobro de clíticoéo sujeito estrutural corresponder ao sujeito temático da sentença. O clítico em Marubo não copia os traços de um sujeito não agente de verbos intransitivos (ver dados em COSTA, 1998, p. 68). 
As formas pronominais átonas da língua reproduzem, assim, os traços formais do argumento verbal externo, descrito, em termos semânticos, como o agente ou o experienciador do evento descrito pelo predicado. Os contornos assumidos pelo fenômeno em causa sinalizam que o clítico duplica os traços de pessoa e número dos pronomes pessoais livres. Essa informação sustenta a exclusão do traço [gênero] do sistema pronominal pessoal dependente e livre. Sua exclusão também recebe confirmação no fato de as formas pronominais átonas e tônicas da língua não imporem restrições quanto ao gênero dos seus referentes (COSTA, 1998). O problema passa a ser a descoberta da organização estrutural dos traços [pessoa] e [número]. O exame das características morfossintáticas das formas pessoais dos pronomes fornece caminhos para a solução do problema. Nesse sentido, o comportamento aparentemente desviante da terceira pessoa em relação à $1^{\mathrm{a}} \mathrm{e} 2^{\mathrm{a}}$ pessoas tem explicação pelo próprio modo de organização estrutural de seus traços. O quadro (ix) recupera as formas da terceira pessoa livres e dependentes. Observa-se que esse quadro assinala a possibilidade de analisar /arasiN/ ( 3 a p. coletivo) como bimorfêmico. A segmentação dessa forma em /a-/ ( $3^{\text {a }}$ p.) e /-rasiN/ (coletivo) sustenta em parte uma análise bimorfêmcia. Essa análise requer justificativa nos aspectos distribucionais das formas em consideração. Essa justificativa é obtida na medida em que o formativo /a-/ aparece consistentemente como a forma da terceira pessoa, ao mesmo tempo em que /-rasiN/ surge como um elemento gramatical que imprime uma noção responsável pela informação referente a número nos NPs da língua. Os dados em (20) (COSTA, 1992, p. 118, 227) ilustram a distribuição do morfema/-rasiN/ entre os nomes.

(ix) Terceira pessoa

\begin{tabular}{|l|c|c|c|c|}
\cline { 2 - 5 } \multicolumn{1}{c|}{} & \multicolumn{2}{c|}{ Singular } & \multicolumn{2}{c|}{ Plural } \\
\cline { 2 - 5 } \multicolumn{1}{c|}{} & tônico & átono & tônico & átono \\
\hline $3^{\text {a }}$ pessoa & $\mathrm{a}$ & aN & arasiN & atuN \\
\hline
\end{tabular}

(20)a. ă

aiNvo-rasiN
mulher-coletivo.
'mulheres'
[mulherada]

b. 'vũnŭrăsĭ vini-rasiN homem-coletivo. 'homens' [homenzada] c. 'vākŭr , sĩ vaki-rasiN criança-coletivo. 'crianças' [criançada] 
Contudo, a interpretação do elemento gramatical /a-/ como a expressão do pronome de $3^{\mathrm{a}}$ pessoa é problemática. Os dados (21) e (22) (COSTA; DORIGO, 2005, p. 73) chamam atenção para a natureza dêitica do formativo /a-/. O quadro (x), elaborado com base em COSTA, 1998, p.59, reúne o conjunto de formas dêiticas da língua.

(x) Dêixis espacial

\begin{tabular}{|l|l|}
\hline na & Próximo e visível da pessoa que fala. \\
\hline wa & Distante e visível da pessoa que fala. \\
\hline a & Distante e invisível da pessoa que fala. \\
\hline
\end{tabular}

(21) na

'kantina

't $\mathrm{anu}$

'na

na

kaNti-na

t $\int a n u$

'na

dem.

arco-foco

nome próprio

de

'Este arco é de t tanu.'

(22)

\begin{tabular}{|c|c|c|c|c|}
\hline wa & 'japa & 'kukipa & na'nina & a'kumpa \\
\hline wa & japa & kuki-pa & na'ni-na & akuNpa \\
\hline & pei & cesta-loc. & Dentro-foco & róprio \\
\hline
\end{tabular}

Além de sua natureza dêitica e de dividir o formativo que codifica a informação de coletivo nos nomes, outra singularidade da terceira pessoa pronominal é a realização de uma noção de plural não ordinário através do morfema /-vu/ afixado ao verbo. Costa (1992, seção 3.1.4.1) descreve esse morfema como a manifestação de um plural indefinido ou generalizado. A necessidade de se recorrer a um formativo próprio como estratégia de indeterminação indica que a terceira pessoa é ela própria determinada. As características gramaticais reveladas pela terceira pessoa na língua Marubo assemelham-se às propriedades exibidas por ela nos demais membros da família Pano sob investigação. Também para o Matsés não é viável a exclusão formal do traço [pessoa] das formas plenas da terceira pessoa correferencial /abi/ $\left(3^{\mathrm{a}}\right.$ p. abs.) e /anbi/ ( $3^{\text {a }}$ p. erg.). E, como discutiremos na seção 3.3, a impossibilidade de exclusão formal do traço [pessoa] da terceira pessoa em Marubo e em Kaxinawá torna evidente que a proximidade entre seus sistemas pronominais não deve ser interpretada, tão somente, como um caso de homofonia entre 
formativos. O comportamento verificado nos pronomes dessas duas línguas vai ao encontro do debate iniciado por Benveniste sobre a natureza dos pronomes e as relações de pessoa no verbo. Seu trabalho expõe que há uma preferência pela interpretação referencial definida das formas correspondentes a 'eu' e 'você', e resistência dessas formas a processos de indeterminação postos em prática através da perda das noções de primeira e segunda pessoas, respectivamente. Contudo, é necessário lembrar que o esvaziamento da noção de pessoa esperado para o termo correspondente a 'ele' só é possível nas gramáticas das línguas Marubo e Kaxinawá através da presença de um formativo próprio. Esvaziamento semelhante ocorre, por exemplo, com o termo 'você', em português, que, em um uso que vem substituindo cada vez mais seu emprego ordinário, deixa de expressar a segunda pessoa e passa a ser empregado como uma forma de indeterminação.

As formas átonas da terceira pessoa em Marubo estão em distribuição complementar com o modo de pluralização operada por /-vu/. O fato de as formas átonas de terceira pessoa se afixarem a verbos em que o formativo /-vu/ não esteja presente pode ser explicado como consequência da exigência de que o clítico dobre somente os traços de constituintes determinados. O dados (23) e (24) (COSTA, 1992, p. 118) mostram que o formativo que expressa coletivo /-rasiN/ e o morfema /-vu/ coocorrem na mesma sentença. O dado (25) (COSTA, 1992, p. 117) acrescenta, contudo, a informação de que a coocorrência entre /-rasiN/ e /-vu/ está sujeita à condição de que não haja reduplicação dos traços de terceira pessoa do sujeito pela forma pronominal átona plural /atu/ cliticizada ao verbo pela esquerda. A pluralização realizada com/-vu/é tanto uma forma de impessoalização do verbo quanto um modo de indeterminar o nome, como mostram os dados (26) e (27), respectivamente (dados de COSTA 1992, p. 119; COSTA, 1992, p. 109).

\begin{tabular}{|c|c|c|c|}
\hline $\begin{array}{l}\text { ăı̆vŏrs̆i } \\
\text { aiNvo-rasiN } \\
\text { mulher-coletivo }\end{array}$ & $\begin{array}{l}\text { ăf'kẽsi } \\
\text { a ''ka-si } \\
\text { todas-modo }\end{array}$ & $\begin{array}{l}\text { ku'kā? } \\
\text { ku'ka } \\
\text { cantar }\end{array}$ & $\begin{array}{l}\text { \ّkivŏ? } \\
\text { iki-vu } \\
\text { aux.-coletivo }\end{array}$ \\
\hline das as mulh & ão canta & & \\
\hline
\end{tabular}


(24)

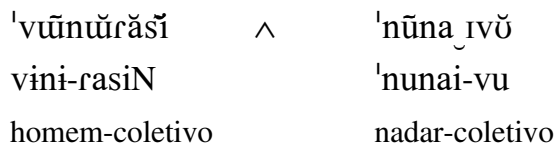

'Os homens estão nadando.'

[A homenzada está nadando.]

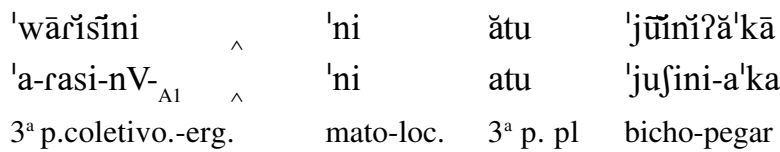

'Eles pegam bicho no mato.'

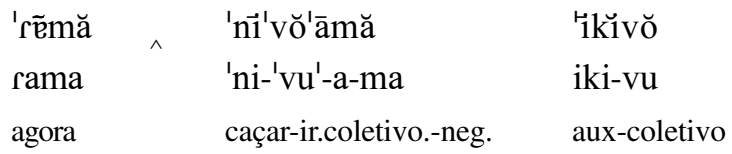

'Ninguém foi caçar hoje.'

(27) 'jüinıัvŏ

'juSini-vu

bichos-coletivo

'Todos os bichos'

A discussão anterior pretende ilustrar que o mecanismo de indeterminação em Marubo configura uma estratégia gramatical própria. A necessidade de se recorrer a uma mecanismo gramatical próprio de indeterminação na língua revela que a determinação não poderia ser de natureza subespecificada. Nesse sentido, o termo correspondente a 'ele' acentuado ou átono também não poderia ser subespecificado para a noção de pessoa. Contudo, a terceira pessoa apresenta características estruturais próprias que a separam da $1^{\mathrm{a}} \mathrm{e} 2^{\mathrm{a}}$ pessoas. Entre essas características está a presença de um elemento sintático que codifica a noção de coletivo/-rasiN/. A coocorrência desse formativo gramatical com o pronome dêitico indica que a noção correspondente a coletivo se realiza fora do lexema utilizado para expressar a terceira pessoa. O pronome /atuvu/ ( $3^{\mathrm{a}} \mathrm{p}$. coletivo indeterminado) corrobora a hipótese sobre a existência sintática independente da noção de número. $\mathrm{O}$ aparecimento do morfema de coletivo indeterminado /-vu/ junto ao pronome é mais uma prova de que noção de número tenha posição estrutural própria dentro do DP. Com o objetivo, então, de registrar as 
características gramaticais da terceira pessoa livre e dependente é proposta a organização estrutural vista em (xi). Nessa representação, as formas plenas de terceira pessoa são a projeção de um núcleo $\mathbf{D}$ especificado com o traço [definido]. Ao lado do núcleo $\mathbf{D}$, é projetado um $\mathbf{Q P}$, que se encontra associado a um núcleo sintático diferente e com projeção própria no interior do DP. A complexidade estrutural da terceira pessoa é resultado de suas semelhanças sintáticas com os nomes. Graças a essas semelhanças, a análise do NP como contendo a projeção funcional de um DP é facilmente acomodada nos dados da língua. A diferença entre as formas plenas de terceira pessoa e os nomes está na projeção de um NP.

(xi)

$3^{\text {a }}$ pessoa

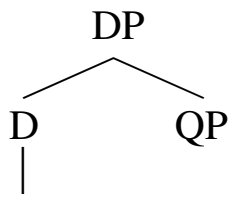

[definido]

[pessoa]

A $1^{\mathrm{a}}$ e $2^{\mathrm{a}}$ pessoas não realizam completamente as propriedades atribuídas à terceira pessoa. Os termos utilizados para 'eu' e 'você' comportam-se como pessoas na língua, que estão restritas, em termos semânticos, ao eixo falanteouvinte. As formas do plural conservam o traço [pessoa]. O termo para 'vocês' e o pronome /nukí/ ( $1^{\text {a }}$ p. pl.) não admitem o cancelamento desse traço pela afixação de /-vu/ (coletivo heterogêneo) no verbo. O cotejo do quadro (xii) com as formas clíticas e livres da terceira pessoa indica que o plural da primeira pessoa e da segunda pessoa não surge da sua combinação com o morfema /-rasiN/. A falta de produtividade do morfema /-tu/ - potencial candidato para a expressão de uma noção correspondente a número - desfavorece o tratamento dessa noção como realizada por uma categoria sintática própria. 
(xii) $1^{\mathrm{a}} \mathrm{e} 2^{\mathrm{a}}$ pessoas

\begin{tabular}{|l|c|c|c|c|}
\cline { 2 - 5 } \multicolumn{1}{c|}{} & \multicolumn{2}{c|}{ Singular } & \multicolumn{2}{c|}{ Plural } \\
\cline { 2 - 5 } \multicolumn{1}{c|}{} & tônico & átono & tônico & átono \\
\hline $1^{\text {a }}$ pessoa & ia & $\grave{\mathrm{iN}}$ & nukì & nuN \\
\hline $2^{\mathrm{a}}$ pessoa & $\mathrm{mia}$ & $\mathrm{miN}$ & matu & $\mathrm{maN}$ \\
\hline
\end{tabular}

Os fatos supra-arrolados impedem o tratamento unificado dos pronomes pessoais em Marubo. O quadro (xiii) mostra que a diferença na organização estrutural dos traços da $1^{\text {a }}$ e $2^{\text {a }}$ pessoas substitui a complexidade estrutural verificada na terceira pessoa. A presença das noções de pessoa e número nos termos utilizados para 'eu' e 'você' indica que a primeira e a segunda pessoas sejam a projeção de um DP como representado na sequência a seguir. A comparação entre as estruturas propostas para a terceira pessoa, de um lado, e para as duas outras pessoas, de outro lado, anuncia que a diferença em jogo é, sobretudo, estrutural, ou seja, a questão é como os traços são organizados no interior do DP.

(xiii) $1^{\mathrm{a}}$ e $2^{\mathrm{a}}$ pessoas

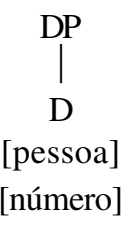

\subsection{Núcleo funcional D a estrutura do DP em Kaxinawá}

A análise dos pronomes e da concordância em Matsés e em Marubo sustenta que os traços comumente associados a uma categoria não precisam estar necessariamente especificados. A hipótese do DP sobre a estrutura interna dos nomes e pronomes baseia-se no paralelismo entre a sentença e o NP, e nas propriedades distribucionais dos traços ordinários dos membros da categoria $\mathbf{D}$. O problema é descobrir se a análise da estrutura interna dos pronomes em Kaxinawá como um DP confirma a tendência de se atribuir às diferenças dos traços formais dos núcleos categoriais a razão pela variação interlinguística. As características distribucionais e morfossintáticas dos pronomes dessa língua esclarecem que os pronomes de sujeito e de objeto são formados pela mesma 
raiz, pertencendo ao mesmo paradigma morfológico (classe lexical). As diferenças existentes entre eles são de ordem sintagmática (sintática). O quadro (xiv) referente às formas pessoais dos pronomes sinaliza para a invariância no plano paradigmático, ao mesmo tempo em que alerta para variabilidade sintagmática. Confira:

(xiv) Sistema de pronomes pessoais

\begin{tabular}{|c|c|c|}
\hline & Singular & Plural \\
\hline & \multirow[b]{2}{*}{$\dot{\mathrm{i}}$} & sujeito \\
\hline $1^{\mathrm{a}}$ pessoa & & $\mathrm{nu}$ \\
\hline $2^{\mathrm{a}}$ pessoa & $\mathrm{mi}$ & $\mathrm{ma}$ \\
\hline $3^{\mathrm{a}}$ pessoa sujeito & - & - \\
\hline $3^{a}$ pessoa objeto & - & hatu \\
\hline & & ha-bu \\
\hline
\end{tabular}

A invariabilidade no plano paradigmático é o que se espera de elementos gramaticais que sejam membros de uma mesma classe. Os pronomes sujeito e objeto pertencem à categoria $\mathbf{D}$. A expressão de posse na língua fornece argumentos para tratar os pronomes como membros dessa classe. As construções em (28) (dados de CAMARGO, 2005, p. 217) exemplificam um tipo de estrutura possessiva na língua. ${ }^{20}$ Observa-se, nessas construções, que a marca de posse /-n/ pode ocorrer com o pronome. A coocorrência dos pronomes com a da marca de posse implica que, ao contrário do que prevê a análise de Abney (ABNEY, 1987, seção 4.4) sobre a organização do DP, esses elementos gramaticais podem constituir núcleos funcionais distintos. A restrição sobre a simultaneidade entre o elemento gramatical 's e o artigo definido no genitivo saxão do inglês John's father ('O pai de John') leva Abney a considerá-los como pertencentes ao núcleo D. A competição pela mesma posição estrutural seria a causa da agramaticalidade da construção *The John's father. As construções de posse em Kaxinawá, contudo, frustram a expectativa de que o correspondente semântico do verbo ter 's seja um membro da categoria D. A língua fornece subsídios para sustentar a hipótese alternativa sobre a presença de um POSSP no interior do DP. 
(28)

\begin{tabular}{|c|c|c|}
\hline a. ə-n & bakə & b. mi-n \\
\hline$\dot{\mathrm{i}}-\mathrm{n}$ & baki & mi-n \\
\hline $\begin{array}{l}1^{\mathrm{a}} \text { p.sg. -poss. } \\
\text { 'Meu filho.' }\end{array}$ & filho & $\begin{array}{l}2^{\text {a }} \text { p. sg.-poss. } \\
\text { 'Seu filho.' }\end{array}$ \\
\hline c. nuku-n & baki & d. matu-n \\
\hline nuku-n & baki & matu-n \\
\hline $\begin{array}{l}1^{\text {a }} \text { p. pl.-poss. } \\
\text { 'Nosso filho.' }\end{array}$ & filho & $\begin{array}{l}2^{\text {a }} \text { p. pl.-poss. } \\
\text { 'O filho de } v\end{array}$ \\
\hline
\end{tabular}

A combinação do pronome com a marca de posse, que não acidentalmente é a mesma da expressão da ergatividade em línguas da família Pano, indica que o afixo responsável pela interpretação genitiva do nome corresponde a uma categoria sintática própria dentro do DP. A variação dos pronomes no plano sintagmático é importante na descoberta dos traços que constituem os membros da categoria $\mathbf{D}$. As diferenças sintagmáticas aparecem condicionadas pela função sintática dos pronomes, se sujeito ou objeto. O pronome sujeito é um clítico despojado das marcas que Camargo (1991, p. 188-192; 1999b) trata como formas de pluralização na língua. O interessante é a ausência dessas marcas não implicar a perda da noção gramatical de plural. Cabe observar que o pronome sujeito topicalizado mantém a sua forma plena e tem os seus traços copiados por outra categoria pronominal. O problema que se apresenta, então, é a descoberta do verdadeiro estatuto sintático das marcas que acompanham as formas despojadas dos pronomes. Devido ao fato de a terceira pessoa ser uma forma dêitica na língua, a análise dos traços que compõem os pronomes inicia-se com a $1^{\mathrm{a}}$ e a $2^{\mathrm{a}}$ pessoas.

$\mathrm{O}$ quadro (xv) repete as formas pronominais de primeira pessoa e segunda pessoa. O destaque é a diferença morfológica do plural das formas correspondentes a 'eu' e 'você' nas funções sintáticas de sujeito e de objeto. Essa diferença é atribuída à presença das marcas /-ku/ e /-tu/, glosados como plural na língua por Camargo (1991, 1999b). Ora, se as evidências para se descobrir à qual categoria funcional pertence determinado afixo são obtidas entre línguas geneticamente relacionadas, a pista sobre o estatuto morfossintático de um elemento gramatical também pode ser alcançada do mesmo modo. Alíngua Kaxinawá compartilha com o Marubo e o Matsés a mesma forma cognata do pronome correspondente a 'nós'. O pronome/nuku/, do Kaxinawá, corresponde 
ao pronome /nuki/, do Marubo, e ao pronome/nuki/, do Matsés, à exceção dos traços fonológicos relativos à vogal final. ${ }^{21} \mathrm{O}$ estudo do sistema pronominal Marubo mostrou não haver razões para tratar a noção de número como um traço com núcleo independente nos pronomes de $1^{\mathrm{a}}$ e $2^{\mathrm{a}}$ pessoas. A língua Matsés corrobora a hipótese de que as categorias particularizadas pelo traço [pessoa] tendam a projetar apenas o núcleo $\mathbf{D}$. As características genéticas, aliadas ao fato de não haver evidências empíricas que sustentem que /-ku/ tenha passado a um modo de pluralização em Kaxinawá, justificam analisar o plural como um traço do núcleo D. De forma análoga, a marca /-tu/ também não pode ser compreendida como a manifestação do plural. $\mathrm{O}$ recurso às propriedades compartilhadas entre os membros da família em pauta prova, mais uma vez, que o melhor é não associar a noção de plural ao/tu/ que ocorre em /matu/ 'vocês' e/hatu/ 'eles (objeto)'. A exclusividade dessa marca no pronome correspondente a 'vocês' denuncia sua natureza lexical. A opacidade sintática da $2^{\mathrm{a}}$ pessoa do plural é sustentada com base em evidências genéticas. Em Marubo, o clítico / ma/ (vocês) nada mais é do que a forma reduzida do pronome /matu/ (vocês).

(xv) $1^{\mathrm{a}}$ e $2^{\mathrm{a}}$ pessoas

\begin{tabular}{|c|c|c|c|}
\hline & Singular & \multicolumn{2}{|c|}{ Plural } \\
\hline & & sujeito & objeto \\
\hline $1^{\mathrm{a}}$ pessoa & $\dot{\mathbf{i}}$ & nu & nuku \\
\hline $2^{\mathrm{a}}$ pessoa & $\mathrm{mi}$ & $\mathrm{ma}$ & matu \\
\hline
\end{tabular}

Como mencionado anteriormente, a terceira pessoa representa uma forma dêitica na língua. O pronome/ha/é da ordem dos demonstrativos. Sua distribuição entre os pronomes pessoais é possível, porque ambos integram a categoria $\mathbf{D}$. A singularidade da terceira pessoa não está restrita à sua natureza dêitica. $\mathrm{O}$ quadro (xvi), a seguir, propõe um recorte desse elemento gramatical para tornar mais evidentes suas particularidades diante dos demais pronomes. Observa-se, nesse quadro, que, mesmo diante da possibilidade de a terceira pessoa sujeito se realizar plenamente através do elemento gramatical/ha/, a preferência é pela sua não materialização fonética - com ou sem a concomitante incidência de uma morfologia especial no verbo. De forma dessemelhante, a terceira pessoa objeto realizar-se-á plenamente através do pronome dêitico. Outra possibilidade é a terceira pessoa figurar sem matriz fonética, o que também não acarreta o 
surgimento de qualquer modificação no verbo. A simetria entre as funções sintáticas de sujeito e objeto não é a única particularidade dessa pessoa. Outra especificidade da $3^{\text {a }}$ pessoa, segundo Camargo (1991), seria a pluralização através do formativo/-bu/. No entanto, como dissemos na seção 3.1, nas línguas da família Pano, o afixo /-bu/ é documentado como uma forma de coletivo (homogêneo ou heterogêneo). Camargo (1991, p. 188-192) descreve esse sufixo como um plural genérico que se opõe ao formativo/-tu/, que codificaria um plural determinado na língua. Criar-se-ia, assim, uma oposição entre /-tu/ (plural determinado) e/-bu/ (plural indeterminado). A interpretação do elemento /-tu/ como expressão de plural é desfavorecida no contexto da análise desenvolvida neste trabalho.

(xvi) $3^{\text {a }}$ pessoa

\begin{tabular}{|l|l|l|}
\cline { 2 - 3 } \multicolumn{1}{c|}{} & \multicolumn{1}{c|}{ Singular } & Plural \\
\hline $3^{\text {a }}$ pessoa sujeito & - & - \\
\hline $3^{\text {a }}$ pessoa objeto & - & hatu \\
\hline \multicolumn{2}{l}{} & ha-bu \\
\cline { 2 - 3 }
\end{tabular}

O tratamento de /-tu/ como parte dos lexemas utilizados para os termos correspondentes a 'vocês' e a 'eles' é corroborado pelos aspectos compartilhados por membros da família linguística Pano. A semelhança fônica entre os pronomes das línguas Kaxinawá e Marubo justifica a ideia de que a mesma base cognata está na origem dos dois sistemas. O quadro (xvii) compara os sistemas pronominais das duas línguas. A alternância entre as formas /hatu/ ( $3^{\mathrm{a}} \mathrm{p}$. pl. determinado) e/habu/ ( $3^{\text {a }}$ p. coletivo indeterminado), em Kaxinawá, é reencontrada entre as formas /atu/ ( $3^{\text {a }}$ p. pl. determinado) e/atuvu/ ( ${ }^{\text {a }}$ p. pl. indeterminado), em Marubo. Nessa última língua, o formativo/-vu/é tratado como a expressão de um plural indeterminado nos pronomes e nomes, por COSTA, 1992, p. 109. Ora, esse formativo nada mais é do que a forma nativa da língua para o coletivo (homogêneo ou heterogêneo) / -bu/, compartilhado por membros da família Pano. ${ }^{22} \mathrm{Se} /$-vu/ (forma nativa de /bu/ em Marubo) compete pela mesma posição estrutural do elemento/-tu/, não se esperaria a ocorrência de algo como/atuvu/-uma forma perfeitamente gramatical na língua. Arazão da ocorrência de /habu/ ao em vez de/hatubu/, em Kaxinawá, não pode, assim, ser explicada com base na competição pela mesma posição estrutural entre o elemento /-tu/ e o morfema/-bu/. 
(xvii) Sistemas pronominais Marubo e Matsés

\begin{tabular}{|c|c|c|c|c|}
\cline { 2 - 5 } \multicolumn{1}{c|}{} & \multicolumn{2}{c|}{ Marubo } & \multicolumn{2}{c|}{ Kaxinawá } \\
\cline { 2 - 5 } \multicolumn{1}{c|}{} & Singular & Plural & Singular & Plural \\
\hline $1^{\text {a }}$ pessoa & ia & nuki & i & nuku \\
\hline $2^{\text {a }}$ pessoa & mia & matu & mi & matu \\
\hline $3^{\text {a }}$ pessoa & a & atu(vu $)$ & - & hatu/habu \\
\hline
\end{tabular}

A expressão da noção gramatical de número nos nomes é mais um item na lista de argumentos contra o tratamento do formativo /-tu/ como um modo de manifestação do plural em Kaxinawá. Os dados seguintes (dados extraídos de CAMARGO, 1999a, 146-150) revelam que o afixo/-bu/é uma forma consistente de expressão do coletivo nos nomes da língua. Ressalta-se, nesse grupo de dados, o termo/baki/ utilizado para criança. A palavra cognata desse termo em Marubo é/vakì/, assim mesmo, com consoante fricativa em lugar da consoante labial. A alternância /bakì/ (Kaxinawá) ${ }^{23}$ /vaki/ (Marubo) é exatamente o que se espera, se a previsão feita anteriormente de que o que em outros membros da família aparece como/b/, em Marubo corresponde a /v/.
a. baki-bu
b. fuda-bu
c. huni-bu
criança-pl.
corpo humano-pl.
homem-pl.
'As crianças'
'Corpos humanos'
'Homens.'
['criançada']
[conjunto de corpos humanos]
[homenzada]

Em síntese, a existência de situações como as reunidas acima favorecem o tratamento dos elementos /-tu/ e/-ku/ de forma diferente daquela que lhes deu Camargo (1991, p. 191), para o Kaxinawá. Graças à comparação com o seu parente Marubo, as propriedades estruturais dos elementos formativos dos pronomes em Kaxinawá tornam-se mais evidentes. A análise comparativa é justificada na medida em que mostra quais propriedades são específicas a uma determinada língua e quais são compartilhadas pelos demais membros da família. No âmbito dessa comparação, as propriedades estruturais dos pronomes em Kaxinawá não se mostram específicas a essa língua. A proximidade dos pronomes das duas línguas comparadas - proximidade essa revelada pela transparência da base cognata comum envolvida na constituição de seus sistemas - é uma ferramenta importante para a depreensão das propriedades lexicais (imprevisíveis/opacas) e sintáticas (previsíveis/transparentes) dos elementos 
formativos em jogo. Assim, não é acidental que, em Marubo, a forma reduzida /-ma/, correspondente ao pronome livre /matu/ ('vocês'), não perca a noção gramatical de plural. O registro do pronome /atuvu/ ( $3^{\mathrm{a}} \mathrm{p}$. coletivo indeterminado), também em Marubo, em que /-vu/corresponde ao elemento gramatical/-bu/ (coletivo homogêneo ou heterogêneo), seria inesperado caso se mantivesse a premissa de que o elemento /-tu/ e o morfema /-bu/ disputam a mesma posição estrutural. Por último, a exclusividade dos elementos /-ku/ (/nuku/, la p. pl) e / -tu/ (/matu/, $2^{\mathrm{a}} \mathrm{p} . \mathrm{pl}$; /hatu/, $3^{\mathrm{a}} \mathrm{p}$. pl) com as formas do discurso mostra que é mais econômico considerá-los como não sendo a manifestação de uma marcação de plural. A produtividade de /-bu/ entre os nomes revela que essa é a verdadeira forma da expressão de número em Kaxinawá.

Como acontece em Matsés e em Marubo, a informação de gênero também é excluída dos pronomes em Kaxinawá. A expressão de gênero encontra-se codificada somente nos lexemas /huni/ ('homem') /ainbu/ ('mulher') /biní/ ('macho')/fușan/ ('fêmea'). Os lexemas para gênero podem aparecer como um constituinte sintagmático independente ou figurar como um dos membros de um composto constituído por um processo de incorporação nominal, conforme verificado nos dados em (30), a seguir (dados de CAMARGO, 1999a, p. 145). A consequência é que informação de gênero dispõe de entrada própria no léxico da língua, correspondendo a uma categoria substantiva. Nossa proposta é que, por possuírem entrada própria no léxico substantivo, os lexemas referentes à informação de gênero figurem como palavras independentes nos processos de incorporação nominal realizados dentro do DP. O traço [gênero] não se associa, assim, a uma posição estrutural própria no interior do DP. O fato de a noção de gênero aparecer como uma categoria substantiva é um impedimento para apresentar propriedades funcionais, como a projeção de uma posição estrutural própria e a capacidade de selecionar outras categorias. Essa é uma evidência empírica para a proposta de que a noção de gênero seja um traço do nome. ${ }^{24}$
a. baki huni
b. baki ainbu
c. takada bini
d. takada jusan
criança homem
criança mulher
galináceo macho
galináceo fêmea
'Menino.'
'Menina.'
'Galo.'
'Galinha.'

O exame dos pronomes em Kaxinawá confirma a tendência verificada em outros membros da família Pano de que os traços comumente relacionados a uma categoria não precisam estar necessariamente presentes no núcleo funcional 
com o qual se associam. A investigação da distribuição e da organização dos traços de pessoa, número e gênero também comprova que o que caracteriza os pronomes como membros das classes dos determinantes é a presença do traço categorial D. A coocorrência dos pronomes pessoais com a marca/-n/ - utilizada para a expressão de posse - sugere que esses dois elementos gramaticais ocupem posição estrutural distinta dentro de DP. A organização estrutural da $1^{\text {a }}$ e $2^{\mathrm{a}}$ pessoas do discurso reforça a proposta de que os pronomes sejam puramente a projeção da categoria $\mathbf{D}$, à qual se associam os traços de [pessoa] e [número]. As características lexicais dos elementos formativos /-ku/ (/nuku/, 'nós') e /-tu/ (/matu/, 'vocês') não são compatíveis com a possibilidade de a noção de número vir a constituir uma projeção independente, isto é, um NumP, na estrutura proposta para a primeira e segunda pessoas (ver (xviii)):

(xviii) $1^{\mathrm{a}}$ e $2^{\mathrm{a}}$ pessoas

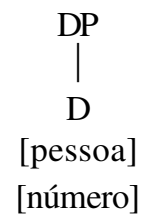

As diferenças na organização e na distribuição dos traços da $1^{\mathrm{a}}$ e $2^{\mathrm{a}}$ pessoas, por um lado, e da terceira pessoa, por outro lado, atestam a existência de duas classes de pronomes. Os termos utilizados para 'eu' e 'você' correspondem a um DP caracterizado por projetar unicamente o núcleo $\mathbf{D}$, ao qual se associam os traços de pessoa e número. A terceira pessoa constitui uma classe própria, caracterizada como um $\mathbf{D P}$ - projeção de um núcleo $\mathbf{D}$, ao qual se ligam os traços [definido] e [pessoa], constituído por um QP. A motivação para a postulação de um QP dentro do DP está na possibilidade de o plural realizado pelo coletivo /-bu/ constituir um núcleo funcional independente nos nomes e pronomes da língua em tela. A ideia de que a noção de coletivo esteja ligada a uma categoria sintática independente tem como implicação o surgimento de uma posição estrutural entre o núcleo D e o NP. Os processos de incorporação nominal que ocorrem dentro de $\mathbf{D P}$ fornecem um argumento empírico para a postulação de semelhante categoria (rever (29)). Outro argumento para QP é o aparecimento de uma marca /-kan/ no verbo, desencadeado pela omissão do 
sujeito de terceira pessoa. ${ }^{25}$ A identificação dos traços projetados pelo núcleo D segue as discussões iniciadas por Benveniste sobre a estrutura das relações de pessoa e sobre a natureza dos pronomes. A investigação do comportamento dos termos correspondentes a 'eu', 'você' e 'ele' como pessoas do discurso e como marcas no verbo levou Benveniste a concluir que a $3^{\text {a }}$ pessoa é a não pessoa. O comportamento singular da terceira pessoa diante das demais pessoas, que pode aparecer sem marca no verbo e sem forma pronominal plena nas línguas naturais, é um argumento empregado para sustentar a tese desse autor. $\mathrm{O}$ traço [pessoa] estabelece uma correlação de personalidade entre a $1^{\mathrm{a}}$ e $2^{\mathrm{a}}$ pessoas, perdida somente em presença de um traço [indefinido]. É assim que, por exemplo, o termo 'você', em português, pode ser esvaziado da noção de pessoa e passar a não pessoa. Portanto, o traço [pessoa] acarretaria o traço [definido], como defende Ritter, 1995, p. 421. Tanto em Kaxinawá quanto em Marubo, assistimos ao esvaziamento da noção de pessoa no termo 'ele' através do mecanismo de pluralização da língua. Cabe ainda acrescentar que a 3 a pessoa pode corresponder a uma forma dêitica nessa língua. A terceira pessoa dêitica (não pessoa) comprova a tese, com origem em Benveniste, de que a noção de pessoa implica a noção de definido, mas a noção de definido não implica a noção de pessoa, como se observa na proposta de representação estrutural em (xix). Na representação a seguir é possível pensar, então, em uma hierarquia em que o traço [definido] domine o traço [pessoa]. ${ }^{26}$

(xix) $3^{\text {a }}$ pessoa

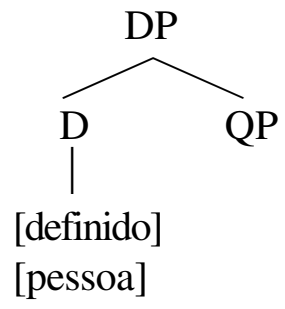

\subsection{Núcleo funcional D a estrutura do DP em Shipibo-Konibo}

O mapeamento morfossintático dos traços-phi dos pronomes da língua Shipibo-Konibo confirma algumas propriedades encontradas em outros membros da família Pano. Essa língua sustenta também algumas previsões feitas sobre organização dos traços-phi nas línguas naturais. As formas despojadas dos 
pronomes pessoais dessa língua são apresentadas no quadro (xx). Aos lexemas dos pronomes, acrescenta-se o morfema de ergatividade $/-\mathrm{n}^{27} /$ para todas as pessoas. A vogal /-a/ aparece exclusivamente nas formas absolutivas da $1^{\mathrm{a}}$ e $2^{\mathrm{a}}$ pessoas do singular (/ia/ 'eu', /mia/ 'você') e na $1^{\text {a }}$ pessoa do plural (/noa/ 'nós'). Valenzuela (2003, seção 6.1.1) identifica essa vogal como uma manifestação morfológica do próprio caso absolutivo nas formas pronominais em que aparece. Contudo, segundo a própria autora (VALENZUELA, 2003, p. 83), essa vogal marca o absolutivo em apenas alguns pronomes, não se estendendo aos nomes. Trata-se, como se vê, de mecanismo improdutivo na língua. Ao lado da improdutividade do formativo /-a/ como uma manifestação de caso absolutivo, outro fato que merece ser observado é a homofonia entre os sistemas pronominais dessa língua com outros membros da família Pano, sobretudo com o Marubo. Observa-se que a $1^{\mathrm{a}}$ e $2^{\mathrm{a}}$ pessoas do singular e a $1^{\mathrm{a}}$ pessoa do plural em suas formas absolutivas correspondem às formas acentuadas dos pronomes pessoais do Marubo. Nesta última língua, o elemento em questão integra os lexemas dos pronomes e figura tanto no caso absolutivo quanto no caso ergativo. A hipótese de que tal segmento também seja parte dos lexemas dos pronomes em Shipibo-Konibo é sustentada pelo próprio sistema pronominal. A alternância de formas documentada por Valenzuela (2003, p. 185) para a $3^{\mathrm{a}}$ pessoa do plural (/hato-n hataon hatoan hatoon/) é uma evidência de que a ausência da vogal /-a/ nas formas ergativas dos pronomes pessoais possa ser fruto de elisão. $\mathrm{O}$ fenômeno da elisão prosodicamente controlado explicaria a ausência do segmento /-a/ nas formas pronominais ergativas e em formas pronominais do absolutivo. Entre os fatores prosódicos que parecem controlar a elisão ou crase de segmentos da língua, podem-se citar o conflito entre a restrição quanto à formação de hiatos e a exigência da satisfação da condição de palavra mínima na língua. Shipibo-Konibo é descrito como uma língua em que a palavra mínima corresponde a duas moras (VALENZUELA, 2003, seção 3.1.5). No caso ergativo, a condição de palavra mínima é satisfeita através da afixação do morfema de ergatividade/-n/, que, mesmo se realizando como ressonância nasal na vogal precedente, conservaria sua unidade de tempo. Conclui-se que a presença do segmento/-a/ nos lexemas pronominais não implica a presença de algum traço adicional além dos traços tradicionalmente associados aos membros dessa categoria. 
(xx) Sistema de pronomes pessoais

\begin{tabular}{|c|c|c|}
\cline { 2 - 3 } \multicolumn{1}{c|}{} & Singular & Plural \\
\hline $1^{\text {a }}$ pessoa & $\dot{\mathrm{i}}$ & no \\
\hline $2^{\mathrm{a}}$ pessoa & $\mathrm{mi}$ & mato \\
\hline $3^{\text {a }}$ pessoa & $\mathrm{ha}$ & haßo $\sim$ hato \\
\hline
\end{tabular}

À semelhança do que acontece com o Matsés, com o Marubo e com o Kaxinawá, a noção de gênero não é codificada no sistema de pronomes ShipiboKonibo. O sistema de pronomes pessoais da língua codifica de modo consistente as interpretações de singular e plural. A noção de número é um traço do sistema pronominal da língua. Como acontece com os demais membros da família Pano analisados neste trabalho, o morfema $/-\beta 0 /{ }^{28}$ expressa a noção de coletivo na língua. Tal morfema aparece como uma forma de pluralização de nomes e pronomes (VALENZUELA, 2003, seções 6.2.2 e 6.6.4). A $3^{\mathrm{a}}$ pessoa do plural é segmentada como /ha- $\beta_{\mathrm{o}} /$ ' $3^{\mathrm{a}}$ p.-pl'. Diferentemente do que acontece em Kaxinawá, em que estão em distribuição complementar, as formas /ha $30 / \mathrm{e} / \mathrm{hato} /$ podem variar livremente. Contudo, Valenzuela identifica contextos que favorecem a utilização da primeira variante. Por exemplo, o pronome /haßo/ é preferencialmente utilizado como anáfora de um conjunto heterogêneo (VALENZUELA, 2003, p. 186). Essa preferência aponta para o fato de o morfema /-ß乃o/ preservar a noção de coletivo heterogêneo nas formas de $3^{\text {a }}$ pessoa da língua. A relativa transparência da noção de plural heterogêneo não parece ser estendida aos nomes da língua. Adistribuição desse morfema entre nomes e pronomes parece ser diferente daquela documentada para o Marubo. Costa (1992) registra para essa última língua dois modos de pluralização. O primeiro modo é realizado através do morfema /-vu/, que aparece junto a verbos e a pronomes e indica conjunto heterogêneo. O outro modo de pluralização é realizado através do morfema/-rasiN/ , que aparece junto a nomes e a pronomes e indica conjunto homogêneo. Em Shipibo-Konibo, ao contrário, o morfema/-ßo/ codifica a interpretação de plural em nomes e pronomes. Contudo, somente na $3^{\mathrm{a}}$ pessoa do plural parece expressar a noção de conjunto heterogêneo. Adiferença na distribuição de /- $\beta \mathrm{o} /$ em relação ao Marubo mostra que esse morfema pode vir a se tornar ou estar se tornando uma forma ordinária de plural na língua. Sua distribuição por um maior número de contextos explicaria, por exemplo, certas ocorrências inesperadas na língua, conforme se pode ver em (31) - (dado de VALENZUELA, 2003, p. 221). 
A língua Shipibo-Konibo também realiza a noção de plural na morfologia verbal. O plural em verbos é marcado por /-kan/, que, também presente em Kaxinawá, aparece junto com a interpretação de um sujeito nulo de $3^{\mathrm{a}}$ pessoa ou com a codificação de um sujeito pleno de $3^{\mathrm{a}}$ pessoa. $\mathrm{O}$ afixo /-kan/ é uma forma de pluralização do sujeito que pode ou não coocorrer com o argumento externo expresso na mesma oração. Tal afixo aparece no verbo da oração encaixada (dado (32)), ocorre em orações com sujeito expresso (dado (33a), e em orações com sujeito de $3^{\mathrm{a}}$ pessoa nulo (dado (33b)) (dados de VALENZUELA, 2003, p. 525, 521 e 221, respectivamente). Ressalta-se que esse afixo, presente na oração encaixada, não se encontra associado à interpretação de nenhum elemento da oração matriz. Dados como esses evidenciam que o morfema/-kan/ pluraliza o sujeito da oração em que aparece. Ao que tudo indica, a noção de número é o único traço desse morfema. A questão então é explicar sua relação com a interpretação de terceira pessoa na língua.

$\begin{array}{llcll}\text { Mato-bo } & \text { moa } & \text { mawat-a } & \text { pekáo } & \text { ik-ai. } \\ \text { mato-ßo } & \text { moa } & \text { mawat-a } & \text { pikao } & \text { ik-ai } \\ \text { 2a p. PL-BO } & \text { já } & \text { morrer-PP2 } & \text { depois } & \text { AUX.I-INC }\end{array}$

'Isto acontecerá depois que vocês todos morrerem'

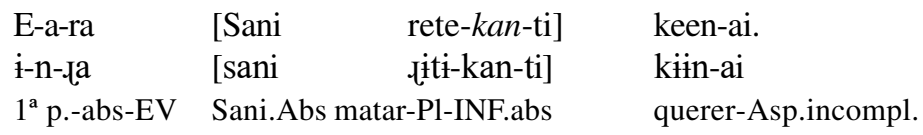

'Eu quero que eles matem Sani.'

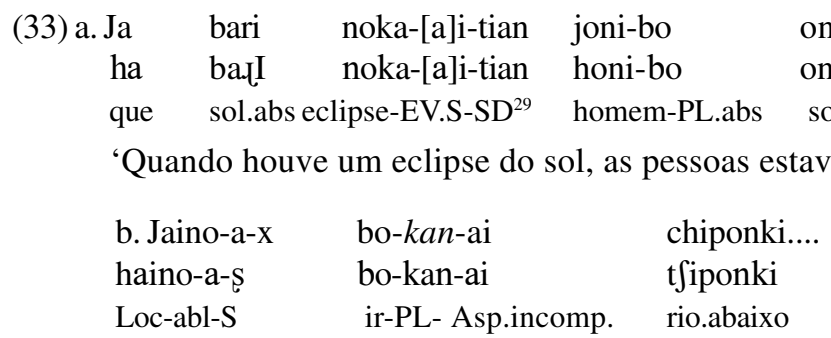

'Então eles desceram o rio ...'

Valenzuela (2003, p 81) mostra que os verbos em Shipibo-Konibo não carregam marcas dos seus argumentos. Com isso, os argumentos verbais são preferencialmente expressos na oração. A ausência de algum desses argumentos aciona automaticamente uma interpretação de sujeito ou objeto nulo de $3^{\mathrm{a}}$ 
pessoa na língua, conforme mostram os dados (34) e (35), respectivamente (dados de VALENZUELA, 2003, p. 345). Todavia, a omissão de argumentos verbais acompanhada pela presença do sufixo /-kan/ faz surgir uma interpretação de sujeito nulo de $3^{\text {a }}$ pessoa plural. A relação desse morfema com a interpretação de $3^{\text {a }}$ pessoa não o impede de aparecer em verbos de construções impessoais, como orações passivas. A associação entre /-kan/ e a terceira pessoa não impede também que esse afixo figure como plural de construções recíprocas (VALENZUELA, 2003, p. 522), reflexivas (VALENZUELA, 2003, p. 267) e nominalizadas (rever dado (32)). A distribuição do elemento gramatical/-kan/ não é incompatível à interpretação de $3^{a}$ pessoa. Contudo, não é plausível admitir que tal elemento esteja associado aos traços de pessoa e número na língua em tela. A questão passa a ser a descoberta das propriedades dos traços pronominais que explicam a relação do morfema /-kan/ com a interpretação de $3^{\mathrm{a}}$ pessoa em ShipiboKonibo.

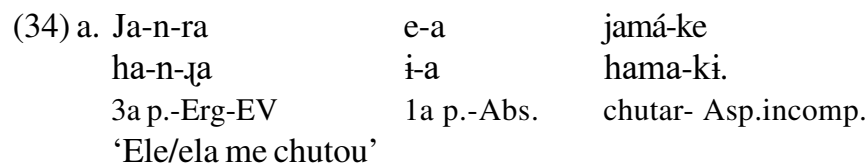

b. E-a-ra jamá-ke.

i-a-ła hama-ki

$1^{\mathrm{a}}$ p.-Abs-EV chutar-Asp.comp.

'Ele/ela me chutou'

(35) a.

$\begin{array}{lll}\text { E-n-ra } & \text { já } & \text { jamá-ke. } \\ \text { i-a-ła } & \text { ha } & \text { hama-ki } \\ \text { 1a p.-Erg.-EV } & \text { 3a. p.Abs } & \text { chutar-Asp.comp. } \\ \text { 'Eu chutei ele/ela/isso' } & \end{array}$

b. E-n-ra jamá-ke.

i-n-ja hama-ki

$1^{\text {a }}$ p.-Erg-EV chutar-comp.

'Eu chutei ele/ela/isso'

Para descobrimos os traços que compõem o morfema /-kan/ e sua compatibilidade com a interpretação de $3^{\mathrm{a}}$ pessoa em Shipibo-Konibo, dedicaremos algumas palavras ao fenômeno conhecido na literatura como switch 
reference. O termo (switch reference) foi criado por William Jacobsen (1967). ${ }^{30}$ Esse termo é aplicado a línguas cuja mudança de referência do sujeito da oração matriz é obrigatoriamente acompanhada pela presença de um morfema geralmente afixado ao verbo das construções subordinadas. ${ }^{31}$ A mudança de referência costuma ser acompanhada pelo registro de informações semânticas temporais e/ou aspectuais. A escolha do afixo pode indicar o tempo em que foi realizada a ação da oração subordinada (antes, depois ou simultaneamente à ação da oração principal) e indicar também qual a função semântica do sujeito correferencial da oração dependente na oração principal. Finer (1985) oferece uma explicação para a switch reference no âmbito da teoria da regência e ligação. Basicamente, Finer trata os afixos que indicam sujeito correferencial com o sujeito da oração transitiva ou intransitiva como anáforas. Já os morfemas que indicam a falta de correferência entre o sujeito da oração subordinada e o sujeito da oração matriz são tratados como pronomes. Déchaine e Wiltschko (2002) também interpretam esse fenômeno sintático com base em princípios universais da linguagem. Para as autoras, o surgimento de um morfema com propriedades de um DP explica a falta de correferência entre o sujeito da oração principal e o sujeito da oração subordinada. Os morfemas que indicam switch reference são tratados como DPs e obedecem ao princípio $\mathbf{C}$ da gramática. Já os morfemas que indicam a mesma referência são interpretados como a manifestação pura dos traços-phi. Estes afixos obedecem ao princípio B da gramática. Finer (1985) e Déchaine e Wiltschko (2002) analisam a switch reference como um fenômeno da sintaxe intersentencial sujeito aos princípios universais da gramática. Diferentemente, Roberts (1988) considera que esse mecanismo é mais bem tratado como um dispositivo intersentencial da dêixis discursiva. $O$ fato de a switch reference ser um fenômeno que aparece também em orações coordenadas e leva em consideração informações relacionadas ao hic et nunc da enunciação sustentam a proposta de Roberts.

Como outras línguas da família Pano, a língua Shipibo-Konibo apresenta o fenômeno de switch reference. Nessa língua, esse fenômeno caracteriza-se pelo aparecimento de um conjunto de morfemas cuja presença no verbo é motivada pela preservação ou mudança de referência do sujeito da oração principal na oração subordinada. Segundo Valenzuela (2003, capítulo 9), a língua apresenta dois conjuntos de morfemas, um conjunto que indica que sujeito da oração subordinada é correferencial com o sujeito da oração matriz, e outro 
conjunto que indica que o sujeito da oração subordinada é não correferencial com o sujeito da oração matriz. Cada conjunto acumula também a informação sobre o tempo em que foi realizada a ação na oração subordinada (antes, depois ou simultaneamente à ação da oração principal). O sistema de referência verbal em Shipibo-Konibo distribui-se nos eixos correferencial e não correferencial. A questão é descobrir se há nessa língua evidências que corroborem o tratamento desses dois sistemas com base em princípios universais da gramática.

O cruzamento da informação sobre o tempo em que foi realizada a ação na oração subordinada (antes, depois ou simultaneamente à ação da oração principal) com transitividade do verbo da oração principal e a natureza funcional ( $\mathrm{S} / \mathrm{A}$ versus $\mathrm{O}$ ) do argumento correferencial da oração encaixada determina a escolha do morfema correferencial (VALENZUELA, 2003, p. 429). Contudo, a existência de um conjunto de morfemas neutros revela que transitividade verbal nem sempre é levada em consideração para a escolha do afixo que indica mesma referência. A transitividade verbal é irrelevante para a escolha dos morfemas que indicam switch reference. Os morfemas correferenciais também aparecem em palavras com função adverbial. O fato de palavras com função adverbial também receberem afixos correferenciais, contradizendo uma das características dos advérbios, é uma surpresa, como destaca Valenzuela (2003, p. 371). Resumindo, temos que, em Shipibo-Konibo, os morfemas relacionados ao eixo correferencial aparecem tanto no nível interoracional quanto no nível intraoracional. No nível interoracional, o morfema escolhido indica a correferência entre o sujeito da oração matriz com o sujeito (ver dado (36a), VALENZUELA, 2003, p. 526) ou o objeto da oração encaixada (ver dado (36b), VALENZUELA, 2003, p. 424). No nível intraoracional, a escolha do morfema indica se o conteúdo nocional dos termos na função de adjunto está ou não semanticamente orientado para o sujeito (S/A) (ver dado (36c) extraído de VALENZUELA, 2003, p. 374). A obrigatoriedade de vinculação no domínio intra ou interoracional revela uma diferença sintática entre os morfemas que indicam a manutenção tópica do sujeito e os que indicam sua descontinuidade.

\begin{tabular}{|c|c|c|c|}
\hline 36) a. E-a-ra & [Mane & tima- $a x]$ & paké-ke. \\
\hline $\begin{array}{l}\mathrm{i}-\mathrm{a}-\_\mathrm{a} \\
1^{\mathrm{a}} \text { p.-Abs-EV }\end{array}$ & $\begin{array}{l}\text { mani } \\
\text { Mane.Abs }\end{array}$ & $\begin{array}{l}\text { tia-as } \\
\text { bater-S }\end{array}$ & $\begin{array}{l}\text { paki-ki } \\
\text { causar.ca }\end{array}$ \\
\hline
\end{tabular}

'Eu bati em Mane e cai.' 


\begin{tabular}{|c|c|c|}
\hline b. $[\mathrm{Ja}-\mathrm{n}$ rao-n- $a]-\mathrm{ra}$ & $\mathrm{e}-\mathrm{a}$ & ka-wan-ke \\
\hline ha-n-.ðao-n-a-.ða & i-a & ka-wanki \\
\hline $3^{\text {a }}$ p.-Erg-medicinal-TRNZ-PO $>$ S/A-EV ${ }^{33}$ & $1^{\mathrm{a}} \mathrm{p} . \mathrm{-Abs}$ & $\begin{array}{l}\text { ir-Pass. recente- } \\
\text { Aspecto.comp. }\end{array}$ \\
\hline
\end{tabular}

'Ele/ela me tratou com planta medicinal e eu fui'
c. E-n-ra
kachio-xon
ninká-ke.
$1^{\mathrm{a}}$ p.í-n-.ja
katfio-son
ninka-ki
1-Erg-EV
na floresta $-\mathrm{A}$
ouvir-Aspecto.comp

'Eu ouvi isso da floresta.' (Eu estava na floresta)

A natureza dêitica discursiva dos afixos que indicam mesma referência e a switch reference em Shipibo-Konibo é revelada pelas diferentes propriedades apresentadas pelos dois sistemas. A codificação da informação do tempo em que é realizado o evento da oração subordinada tem papel determinante para a escolha do afixo referencial e não referencial. Em contrapartida, a transitividade verbal nem sempre é levada em consideração para a escolha do afixo referencial, sendo a também irrelevante para a escolha dos morfemas que indicam switch reference. A priorização da informação temporal sobre a informação referencial pode ser exemplificada pelo fato de ser o tempo que determina se a transitividade e/ou a pessoa são ou não relevantes para a escolha do afixo e qual o peso dessas duas informações (VALENZUELA, 2003, p. 430-431). A existência dos afixos neutros em relação à transitividade verbal da oração principal é mais um dado a favor da natureza dêitica discursiva desses morfemas. $O$ fato de os morfemas que indicam mesma referência aparecerem também em palavras com função adverbial reforça a visão dêitica discursiva desses elementos. Assim como outras categorias dêiticas, os advérbios codificam informação espacial ou temporal a partir de um ponto que pode estar localizado no hic et nunc da enunciação. Se, por um lado, a presença de concordância é algo inesperado em membros ou palavras com valor adverbial, por outro lado a codificação de informação dêitica é o que se espera de membros dessa categoria. Portanto, faz-se necessário distinguir entre a natureza dêitica e anafórica dos morfemas referenciais. A conclusão é a de que os sistemas referenciais são dêiticos na língua.

A discussão sobre a switch reference nos esclarece que as propriedades dos sistemas referenciais são mais bem compreendidas se tratarmos os morfemas que codificam informação pessoal no verbo como dêiticos na língua. A natureza dêitica desses elementos explica a ausência de traços de 
concordância no morfema /-kan/. A exclusão de marcas de concordância no verbo é condizente com a hipótese de esse morfema ser uma expressão pura de plural em Shipibo-Konibo. A relação desse morfema com uma interpretação de terceira pessoa é resultado de uma regra default. Diferentes trabalhos defendem que a interpretação de terceira pessoa é consequência natural da ausência de traços relacionados ao eixo falante ( $1^{\mathrm{a}}$ pessoa $)$ e ouvinte $\left(2^{\mathrm{a}}\right.$ pessoa $)$ (BENVENISTE, 1995; HARLEY; RITTER, 2002). Portanto, ausência do eixo pessoal em /-kan/ cria as condições para o surgimento de uma terceira pessoa default na língua.

O sistema pronominal Shipibo-Konibo compartilha as propriedades dos sistemas encontrados em Marubo e em Kaxinawá. A base cognata que deu origem aos pronomes nas três línguas reflete na base material comum a proximidade entre os seus sistemas. Assim como em Marubo e em Kaxinawá, as noções referentes às interpretações de pessoa e número aparecem diretamente codificadas nos lexemas pronominais de $1^{\mathrm{a}}$ e $2^{\mathrm{a}}$ pessoas em Shipibo-Konibo. A representação seguinte (ver (xxi)) mostra que os traços morfossintáticos correspondentes a essas duas interpretações realizam-se no núcleo $\mathbf{D}$. A representação feita para a terceira pessoa mostra que a noção correspondente a número nessa pessoa é realizada fora do núcleo $\mathbf{D}$ como um $\mathbf{Q P}$ (sintagma quantificador).

(xxi)

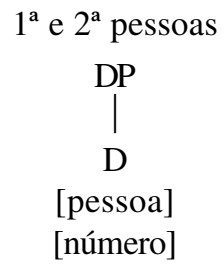

$3^{\mathrm{a}}$ pessoa

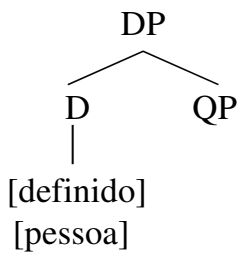

\section{Conclusão}

Neste trabalho, as propriedades lexicais dos sistemas pronominais de quatro línguas da família Pano foram interpretadas em termo de sua estrutura morfológica e da organização de seus traços morfossintáticos com base em um quadro teórico que explica a variação interlinguística (e quiçá intralinguística) em termos de traços não substantivos (formais) com interpretação semântica na gramática. Aideia é a de que as propriedades morfossintáticas dos pronomes são 
explicadas com base nos traços gramaticais que os compõem, os chamados traços-phi. A investigação das propriedades morfossintáticas dos pronomes revelou que em Marubo, Kaxinawá e Shipibo-Konibo a proximidade material de seus pronomes reflete o fato de as três línguas compartilharem o mesmo sistema de traços no núcleo funcional $\mathbf{D}$ e expressarem a noção de número através da projeção de um QP no interior do DP. Em Matsés, a assimetria da $1^{\mathrm{a}} \mathrm{e} 2^{\mathrm{a}}$ pessoas com a $3^{\mathrm{a}}$ pessoa é substituída pela simetria estrutural. A simetria estrutural é acompanhada pela exclusão da expressão da noção de plural em seu sistema pronominal. Obseva-se que a existência do formativo /-kan/ presente tanto em Kaxinawá quanto em Shipibo-Konibo é uma evidência para a exclusão da noção de pessoa no verbo. Apenas a noção de plural aparece codificada em verbos Kashinawá e Shipibo-Konibo. Em Marubo, o fenômeno conhecido na literatura como redobro de clítico garante a codificação da informação de pessoa no verbo através da próclise das formas átonas (fonologicamente dependentes) dos pronomes. Mais uma vez o Matsés afasta-se do conjunto Pano investigado, com o morfema /-S/ que, presente como uma afixo verbal, é uma manifestação da terceira pessoa (singular ou plural) na língua. A ausência da noção de plural no sistema pronominal e na concordância verbal em Matsés recebe confirmação extra pela exclusão da noção de dual na língua. A geometria dos traços dos pronomes proposta por Harley e Ritter (2002) prevê a ausência da noção de dual em línguas nas quais falte a codificação da interpretação de plural, tal como acontece em Matsés. Por último, a maior distribuição do morfema /- $\beta \mathrm{o} / \mathrm{em}$ Shipibo-Konibo aponta para a possibilidade de esse morfema vir a se tornar ou estar se tornando a manifestação de uma forma ordinária de plural, ao contrário do que aconteceria em Marubo.

A investigação das propriedades morfossintáticas dos pronomes (estrutura dos traços e organização interna) mostrou que a consistência da exclusão da noção de número em Matsés é acompanhada pela consistência da inclusão dessa noção no sistema de pronomes pessoais do Marubo, Kaxinawá e em ShipiboKonibo.

A quadro a seguir compara e sintetiza os resultados encontrados sobre a organização e a presença dos traços-phi nas quatro línguas da família Pano investigadas neste trabalho. 
(xxii) Quadro sintático comparativo dos traços-phi em quatro línguas da família Pano

\begin{tabular}{|c|c|c|c|c|}
\hline Traço-phi & Matsés & Marubo & Kaxinawá & Shipibo-Konibo \\
\hline $\begin{array}{l}\text { Traço- phi de gênero no } \\
\text { Sintagma Determinante } \\
\text { (Núcleo D) }\end{array}$ & & & & \\
\hline $\begin{array}{l}\text { Traço-phi de número no } \\
\text { Sintagma Determinante } \\
\text { (Núcleo D) }\end{array}$ & & $\mathbf{X}$ & $\mathbf{X}$ & $\mathbf{X}$ \\
\hline $\begin{array}{l}\text { Traços-phi de pessoa } \\
\text { e definido no Sintagma } \\
\text { Determinante }\end{array}$ & $\mathbf{X}$ & $\mathbf{X}$ & $\mathbf{X}$ & $\mathbf{X}$ \\
\hline $\begin{array}{l}\text { Traços-phi na } \\
\text { concordância verbal }\end{array}$ & \begin{tabular}{|c|} 
Traço de \\
terceira pessoa \\
e exclusão do \\
traço de número
\end{tabular} & \begin{tabular}{|c|} 
Traço de \\
número e \\
exclusão do \\
traço de pessoa
\end{tabular} & \begin{tabular}{|} 
Traço de número \\
e exclusão do \\
traço de pessoa
\end{tabular} & $\begin{array}{l}\text { Traço de número } \\
\text { e exclusão do } \\
\text { traço de pessoa }\end{array}$ \\
\hline $\begin{array}{l}\text { Presença de Sintagma } \\
\text { Quantificador no } \\
\text { interior do Sintagma } \\
\text { determinante }\end{array}$ & & $\mathbf{X}$ & $\mathbf{X}$ & $\mathbf{X}$ \\
\hline $\begin{array}{l}\text { Simetria/ Assimetria } \\
\text { entre os pronomes } \\
\text { pessoais }\end{array}$ & \begin{tabular}{|} 
Simetria \\
estrutural dos \\
pronomes de \\
primeira, \\
segunda e \\
terceira pessoas
\end{tabular} & \begin{tabular}{|c|} 
Assimetria \\
estrutural da \\
primeira e \\
segunda \\
pessoas com a \\
terceira pessoa.
\end{tabular} & \begin{tabular}{|c|} 
Assimetria \\
estrutural da \\
primeira e \\
segunda pessoas \\
com a terceira \\
pessoa.
\end{tabular} & $\begin{array}{c}\text { Assimetria } \\
\text { estrutural da } \\
\text { primeira e } \\
\text { segunda pessoas } \\
\text { com a terceira } \\
\text { pessoa. }\end{array}$ \\
\hline Clíticos & \begin{tabular}{|c|} 
Simples: \\
distribuição \\
complementar \\
com NP \\
\end{tabular} & $\begin{array}{l}\text { Redobro do } \\
\text { clítico }\end{array}$ & $\begin{array}{l}\text { Redobro de } \\
\text { clítico }\end{array}$ & $\begin{array}{c}\text { Os verbos não } \\
\text { carregam marcas } \\
\text { de seus } \\
\text { argumentos }\end{array}$ \\
\hline
\end{tabular}




\section{Notas}

${ }^{1}$ Este artigo tem origem em minha Tese de Doutorado intitulada Núcleos funcionais em línguas da família Pano. Uma abordagem minimalista, defendida no âmbito do Programa de Pós-graduação em Linguística (Faculdade de Letras/UFRJ), em outubro de 2007, e orientada pela Profa. Dra. Marília Facó Soares.

${ }^{2}$ Agradeço aos pareceristas deste artigo os seus comentários/observações e sugestões.

${ }^{3}$ ABNEY, 1987, p. 281-284.

${ }^{4}$ GELDEREN, 1993.

${ }^{5} \mathrm{O}$ fato de o nódulo Individualização dominar o nódulo Classe revela uma dependência deste último nódulo pelo primeiro. Harley \& Ritter (2002, p. 514) explicam que essa dependência é registrada pelo universal 36 de Greenberg, segundo o qual "se uma língua possui categoria de gênero então ela possui categoria de número”.

${ }^{6}$ HAEGEMAN; GUÉRON, 1999, seção 3.3.

${ }^{7} \mathrm{O}$ traço associado à noção semântico-gramatical de número aparece com frequência como um elemento próprio nas formas pronominais de terceira pessoa. A presença de uma morfologia associada a número nos pronomes pessoais de terceira pessoa não parece ser um fato acidental das línguas naturais (BENVENISTE, 1995; RITTER, 1995; HARLEY; RITTER, 2002).

${ }^{8} \mathrm{O}$ morfema $/ \mathrm{t} \int \varepsilon \mathrm{do} /$, que, na representação ortográfica utilizada por Fleck, se grafa como chedo, é glosado como 'também/et cetera', para referir-se a um plural que reúne categorias heterogêneas.

${ }^{9}$ Dorigo (2001) e Fleck (2003, capítulo 2, seções 2.2 e 2.2.2) divergem quanto à interpretação fonológica das vogais médias $[e, \varepsilon]$ e $[o, ~ \jmath]$ da língua Matsés. Baseada no fato de que as vogais coronais e dorsais médias são elevadas em contexto de ressonância nasal, Dorigo opta pela representação fonológica dessas vogais como abertas. Fleck registra a alternância aberta e fechada observada entre as vogais coronais médias como o resultado de um movimento em um contínuo articulatório. $\mathrm{O}$ papel mais importante para o deslocamento articulatório da vogal coronal nesse contínuo é, aparentemente, o da ressonância nasal. Apesar disso, o autor parece encontrar no aspecto articulatório tenso a motivação de sua escolha para o representante fonológico das realizações $[\mathrm{e}] \mathrm{e}[\varepsilon]$ como /e/. Diferenças quanto à produção vocálica tensa na região articulatória dorsal também determinam a interpretação quanto à representação fonológica dessa região. Merece ser mencionado que a vogal dorsal média aberta [0] não consta no quadro de sons levantado para a língua Matsés por Fleck - o que, de alguma forma, influencia sua análise. Devido às diferenças nas interpretações fonológicas 
e, mesmo, nos próprios inventários de sons da fala levantados para essa língua, a alternância na representação fonológica do morfema /-bo/ (coletivo homogêneo ou heterogêneo) é uma consequência natural do fato de estarmos lidando com diferentes fontes de documentação linguística.

${ }^{10}$ A restrição que pesa sobre a presença do clítico /-ben/ junto ao pronome /nuki/ se aplica às formas arcaicas de segunda pessoa plural /mitso/ e /miki/ (FLECK, 2003, seção 4.4.5.1).

${ }^{11}$ Fleck (2003, seção 8.3.4) testou a aceitabilidade da ocorrência do formativo quantitativo/daidi/ ('ambos') com/anbi/ ( $3^{\mathrm{a}} \mathrm{p}$. erg. correferencial), por falantes nativos do Matsés. Alguns dos falantes consultados julgaram inaceitável a combinação dessas duas formas. Como esclarece Fleck (2003, seção 8.3.4), esse julgamento desfavorável apoia a incompatibilidade entre o caso ergativo e o formativo em questão.

${ }^{12}$ A representação subjacente /anbi-ben-tsi-bi/ proposta para ambentsëcbi 'ele sozinho' registra a ocorrência de haplologia entre a sequência final do pronome de terceira pessoa correferencial anbi e o formativo -ben. A haplologia não se encontra originalmente registrada em Fleck (2003, p. 264).

${ }^{13}$ Fleck (2003, p. 264) apresenta a forma segmentada para o termo correspondente a 'ele sozinho', em Matsés, assim: a-n-ben-tsëc-bi (/ a-n-ben-tsik-bi/ $4^{\text {a }}$ p.erg.sozinho-dim.enfático). Ao segmentar as formas da língua em seus elementos constitutivos, o autor recupera a informação sobre a forma fonológica da nasal em coda, em um contexto em que utiliza o sistema ortográfico idealizado pelo SIL. ${ }^{14} \mathrm{O}$ quadro dos traços do sistema pronominal pessoal Matsés aqui apresentado objetiva ser uma síntese dos achados feitos por DORIGO, 1992, notas 6 e 11, e por FLECK, 2003, p. 243, para os pronomes da língua.

${ }^{15}$ A nossa proposta apoia-se em RITTER, 1995.

${ }^{16}$ A dependência da quarta pessoa em relação a oração principal poderia indicar que se trata realmente de um argumento da oração principal. Tal indicação poderia ser sustentada no fato de o argumento da oração principal com o qual a terceira pessoa correferencial está indexada ser não expresso. O problema é a quarta pessoa também aparecer coindexada com um argumento expresso da oração principal. Parece então não haver impedimento sobre a natureza nula ou plena do argumento da oração principal que fornece a referência para a terceira pessoa pronominal plena em Matsés. A presença de constituinte pleno com a mesma relação gramatical que as formas da terceira pessoa pronominal plena estabeleceriam, caso fossem constituintes da oração principal, sustenta a ideia de que elas estejam realmente na oração subordinada.

${ }^{17} \mathrm{~S} / \mathrm{A}>\mathrm{S}$ : indica que o padrão de co-referência com o morfema adverbial /Sun/ ('depois') é entre um participante da oração subordinada identificado como $\mathbf{S}$ 
(sujeito) ou A (agente) e um participante da oração principal identificado como S(sujeito). A verificação desse tipo de co-referência nos permite dizer, ainda que preliminarmente, que estamos diante de uma língua sintaticamente nominativoacusativa. Obviamente, para chegarmos a uma conclusão, precisamos estender nossa análise da co-referencia a outras formas de subordinação, às orações coordenadas, e mesmo, ao fenômeno conhecido como referência cruzada (switch-reference).

${ }^{18}$ As características da quarta pessoa (terceira pessoa correferencial) em Matsés impedem que ela seja analisada como um tipo de do-support. O fenômeno conhecido na literatura como do-support implica a inserção de um verbo expletivo (sem conteúdo semântico) para satisfazer alguma condição sintática. A quarta pessoa também implica a inserção de um elemento para a satisfação de uma condição sintática da oração encaixada de natureza nominal. A diferença é que a quarta pessoa não se comporta meramente como um elemento suporte. A quarta pessoa preserva sua característica pronominal não se comportando como um elemento semanticamente vazio. As características gramaticais da terceira pessoa correferencial assemelham-se às de um PRO controlado.

${ }^{19} \mathrm{~A}_{1}=$ [aberto1]. Na análise fonológica do Marubo, Costa (2000) utilizou o sistema de traços de Clements \& Hume (1995).

${ }^{20}$ A expressão da posse em Kaxinawá é realizada também por meio de construções locativas predicativas, sentenças existenciais e sentenças copulativas (CAMARGO, 1991, p. 350-362; 2005).

${ }^{21}$ Para o Kaxinawá, poder-se-ia dizer que as duas vogais do morfema em causa compartilham em um mesmo plano autossegmental os traços [labial, dorsal]. Já o Marubo ficaria com a especificação [labial] para a primeira vogal e reteria o traço [dorsal] apenas para a segunda vogal (que não é labial). Com relação ao Matsés, a vogal final, em vez de [dorsal], seria simplesmente [coronal]. Evidentemente, falta a esse raciocínio agregar a questão da redundância fonológica, em termos de traços, e a possibilidade de que as vogais foneticamente centrais dessas línguas possam ser fonologicamente não especificadas para ponto de articulação. A respeito desse assunto, veja-se Lanes (2005).

${ }^{22}$ Costa (1998, p. 95) apresenta o quadro de cunho estruturalista a seguir para as consoantes fonológicas do Marubo. O destaque, nesse quadro, é para a classificação do segmento fonológico /v/ como labial. Essa classificação nos parece ser motivada na ausência de oposição entre segmentos labiais e labiodentais, assim: /p/:/f/ e /b/:/v/. Se isso é verdade, podemos levantar a hipótese de que o que em outros membros da família aparece como/b/, em Marubo corresponde a /v/. Essa hipótese sustenta nossa análise de /-vu/ como a forma nativa de um Pano reconstruído /-bu/. 


\begin{tabular}{l|c|c|c|c|c}
\hline & labial & alveolar & Pós-alveolar & Palatal & Velar \\
\hline Oclusivo & $\mathrm{p}$ & $\mathrm{t}$ & & & $\mathrm{k}$ \\
Nasal & $\mathrm{m}$ & $\mathrm{n}$ & & & \\
Fricativo & $\mathrm{v}$ & $\mathrm{s}$ & $\int$ & & \\
Africado & & & $\mathrm{t} \int$ & & \\
Tap & & $\mathrm{r}$ & & & \\
Aproximante & $\mathrm{w}$ & & & $\mathrm{y}$ & \\
\hline
\end{tabular}

${ }^{23}$ A hipótese de que o que em outros membros da família linguística Pano aparece como /b/, em Marubo corresponde a / $/$ / é corroborada pelo sistema fonológico de base estruturalista idealizado para o Kaxinawá por Camargo (1991, p. 96). A ausência de /v/ é compensada pela presença de /b/, no sistema fonológico da língua. A mesma situação repete-se com o Matsés (DORIGO, 2001, p. 127-129; FLECK, 2003, p. 72). Como este trabalho não é de glotocronologia nem aspira a uma reconstrução linguística, nossa preferência é por não mostrar esses quadros aqui.

${ }^{24}$ RITTER, 1995, p. 411.

${ }^{25}$ A presença do formativo $/ \mathrm{kan} /$ como um morfema de plural do verbo em Kaxinawá é exemplificada a seguir (dado extraído de CAMARGO, 1991, p. 191)

$\begin{array}{llll}\varnothing & \text { ia } & \text { nami } & \text { inankanikiki } \\ & \text { i-a } & \text { nami } & \text { inan-kan-iki-k -i } \\ 3^{\text {a }} \text { p. pl. } & 1^{\text {a }} \text { p. sg. acus. } & \text {.carne } & \text { dar-pl.-3 }{ }^{\text {a }} \text { p. declarativo-k-presente } \\ \text { 'Eles me } & \text { dão carne' } & & \end{array}$

'Eles me dão carne'

${ }^{26}$ Agradeço a observação feita por um dos pareceristas deste trabalho.

${ }^{27}$ Valenzuela $(2003$, p. 95 , 98) interpreta as vogais portadoras de ressonância nasal como uma sequência /-Vn/. Uma consequência dessa interpretação é o morfema de ergatividade da língua ser representado como uma nasal com traços de ponto de articulação especificados (/-n/). A possibilidade de línguas Pano terem o morfema de ergatividade nasal especificado para ponto é explorada por COSTAe DORIGO, 2002. ${ }^{28} \mathrm{O}$ morfema /- $\mathrm{\beta o}$ / é a forma nativa do coletivo /-vu/.

${ }^{29} \mathrm{SD}=$ sujeito diferente.

${ }^{30}$ Apud ROBERTS, 1988.

${ }^{31}$ A switch reference não é exclusiva de períodos formados por subordinação.

${ }^{32} \mathrm{~A}=$ sujeito da oração encaixada correferencial com o sujeito da oração transitiva. ${ }^{33} \mathrm{PO}>\mathrm{S} / \mathrm{A}=$ evento anterior à ação da oração principal, objeto da oração encaixada correferencial com o sujeito da oração matriz. 


\section{Referências}

ABNEY, Steven Paul. The English noun phrase in its sentential aspect. PhD dissertation, MIT, Cambridge, Massachusetts, 1987.

ALEXIADOU, Artemis; ANAGNOSTOPOULOU, Elena. Parametrizing AGR: word order, V-movement and EPP-checking. Natural Language and Linguistic Theory, v. 16, p. 491-539, 1998.

ALEXIADOU, Artemis; ANAGNOSTOPOULOU, Elena. The subject-in-situ generalization and the role of case in driving computations. Linguistic Inquiry, v. 32, n. 2, p. 193-231, Spring 2001.

BENVENISTE, Émile. Problemas de lingüística geral I. 4 ed.. Campinas: Pontes, Editora da Universidade Estadual de Campinas, 1995.

BORER, Hagit. I-subjects. Linguistic Inquiry, v. 17, n. 3, p. 375-416, 1986.

BORER, Hagit. Parametric variation in clitic construction. 1981. PhD (Thesis) Institut of Technology, Cambridge, Massachusetts, 1981.

CAMARGO, Eliane. A construção genitiva em Caxinauá (Pano). In: RODRIGUES, Aryon Dall'Igna; CABRAL, Ana Suelly Arruda Câmara (Org.). Novos estudos sobre línguas indígenas. Brasília: Editora Universidade de Brasília, 2005. p. 215-227.

CAMARGO, Eliane. Elementos da base nominal em caxinauá (Pano), 1999a, Ms.

CAMARGO, Eliane. Determinação, posse, pertencimento e atribuição em caxinauá, $1999 \mathrm{~b}, \mathrm{Ms}$.

CAMARGO, Eliane. Phonologie, morphologie et sintaxe. Étude descriptive de la langue Caxinauá (Pano). Université Paris-Sorbonne, 1991.

CHOMSKY, Noam. Derivation by phase. Ms. 1999.

CHOMSKY, Noam. The minimalist program. Cambridge MIT Press, 1995.

CLEMENTS, G. N.; HUME, Elisabeth V. Internal organization of speech sounds. In: The handbook of phonological theory. Blackwell Publishers, 1995.

COSTA, Raquel Guimarães Romankevicius. Padrões rítmicos e marcação de caso em Marubo (Pano). 1992. Dissertação (Mestrado) - Faculdade de Letras, Universidade Federal do Rio de Janeiro, Rio de Janeiro, 1992.

COSTA, Raquel Guimarães Romankevicius. Aspects of ergativity in Marubo (Panoan). The Journal of Amazonian Languages, v. 1, n. 2, p. 50-103, 1998.

COSTA, Raquel Guimarães Romankevicius. Aspectos da Fonologia Marubo: uma visão não-linear. 2000. Tese (Doutorado) - Faculdade de Letras, Universidade Federal do Rio de Janeiro, Rio de Janeiro, 2000. 
COSTA, Raquel Guimarães Romankevicius; DORIGO, Carmem. A expressão da posse em Marubo e Matsés. In: RODRIGUES, Aryon Dall'Igna; CABRAL, Ana Suelly Arruda Câmara (Org.). Novos estudos sobre línguas indígenas. Brasília: Editora Universidade de Brasília, 2005. p. 69-83.

COSTA, Raquel Guimarães Romankevicius; DORIGO, Carmem. A coda nasal em Marubo e Matsés (Pano). Atas do II Seminário Internacional de Fonologia. Porto Alegre: PUCRS, 2002.

DÉCHAINE, Rose-Marie; WILTSCHKO, Marina. Decomposing pronouns. Linguistic Inquiry, v. 33, n. 3, 2002.

DORIGO, Carmen Teresa. A fonologia Matsés. Uma visão segundo a Teoria da Otimalidade. Rio de Janeiro: Faculdade de Letras da UFRJ, 2001.

DORIGO, Carmen Teresa. A decodificação da estrutura frasal em Matsés (Pano). 1992. Dissertação (Mestrado) - Programa de Pós-graduação em Linguística da Faculdade de Letras/UFRJ, Rio de Janeiro, 1992.

FLECK, David William. A grammar of Matsés, PhD Thesis2003. Houston, Texas, 2003.

FLECK, David William. Coreferential fourth-person pronouns in Matses, MS

FINER, D. L. The syntax of switch-reference. Linguistic Inquiry, v. 16, p. 35-55, 1985.

GELDEREN, Elly van. The rise of functional categories. John Benjamins publishing company. Amsterdam/Philadelphia, 1993.

HAEGEMAN, Liliane; GUÉRON, Jacqueline. English grammar. A generative perspective. Blackwell textbooks in linguistics, 1999.

HARLEY, Heidi; RITTER, Elizabeth. Person and number in pronouns: a featuregeometric analysis. Language, v. 78, n. 3, p. 482-526, 2002.

KALLULLI, D. The comparative syntax of Albanian. On the contribution of syntactic types to propositional interpretation. University of Durham, 1999.

LANES, Elden José. Aspectos da mudança linguística em um conjunto de línguas amazônicas: as línguas Pano. Rio de Janeiro: UFRJ, 2005.

ROBERTS, John R. Amele switch reference and the theory of grammar. Linguistic Inquiry, v. 19, n. 1, p. 45-63, 1988.

RITTER, Elizabeth. On the syntactic category of pronouns and agreement. Natural Language and Linguistic Theory, v. 13, p. 405-443, 1995.

VALENZUELA, Pilar M. Transitivity in Shipibo-Konibo Grammar. PhD Thesis, 2003.

Submissão do artigo: 9/1/2010

Aprovação do artigo: 7/12/2011 